\title{
Differential Regulation of circRNA, miRNA, and piRNA during Early Osteogenic and Chondrogenic Differentiation of Human Mesenchymal Stromal Cells
}

\author{
Elena Della Bella ${ }^{1}$, Ursula Menzel $^{1}$, Valentina Basoli ${ }^{1}$, Céline Tourbier ${ }^{1,2}$, Mauro Alini ${ }^{1}$ and \\ Martin J. Stoddart 1,3,*(D) \\ 1 AO Research Institute Davos, 7270 Davos Platz, Switzerland; elena.dellabella@aofoundation.org (E.D.B.); \\ ursula.menzel@aofoundation.org (U.M.); Valentina.basoli@aofoundation.org (V.B.); \\ celine.tourbier@aofoundation.org (C.T.); mauro.alini@aofoundation.org (M.A.) \\ 2 Department of Cranio-Maxiofacial Surgery, Medical Center-Albert-Ludwigs-University of Freiburg, Faculty \\ of Medicine, Albert-Ludwigs-University of Freiburg, 79085 Freiburg, Germany \\ 3 Department of Orthopedics and Trauma Surgery, Medical Center - Albert-Ludwigs-University of Freiburg, \\ Faculty of Medicine, Albert-Ludwigs-University of Freiburg, 79106 Freiburg, Germany \\ * Correspondence: martin.stoddart@aofoundation.org
}

Received: 18 December 2019; Accepted: 6 February 2020; Published: 9 February 2020

\begin{abstract}
The goal of the present study is to identify the differential expression of circular RNA (circRNA), miRNA, and piwi-interacting RNA (piRNA) after lineage commitment towards osteoand chondrogenesis of human bone marrow mesenchymal stromal cells (hMSCs). The cells were maintained for 7 days in either osteogenic or chondrogenic medium. RNA sequencing was performed to assess the expression of miRNA and piRNA, while RNA hybridization arrays were used to identify which circRNA were differentially expressed. qPCR validation of a selection of targets for both osteogenic and chondrogenic differentiation was carried out. The differential expression of several circRNA, miRNA, and piRNA was identified and validated. The expression of total and circular isoforms of FKBP5 was upregulated both in osteo- and chondrogenesis and it was influenced by the presence of dexamethasone. ZEB1, FADS2, and SMYD3 were also identified as regulated in differentiation and/or by dexamethasone. In conclusion, we have identified a set of different non-coding RNAs that are differentially regulated in early osteogenic and chondrogenic differentiation, paving the way for further investigation to understand how dexamethasone controls the expression of those genes and what their function is in MSC differentiation.
\end{abstract}

Keywords: human mesenchymal stem cells; RNA sequencing; circular RNA; miRNA; piwi-interacting RNA; dexamethasone; differentiation; transcriptome; non-coding RNA

\section{Introduction}

Bone marrow-derived mesenchymal stromal cells (MSCs) potentially represent a good source of cells for bone and cartilage tissue engineering. MSCs are widely studied and used in several clinical trials, with $>80$ active trials (clinicaltrials.gov, September 2019) and at least 20 for the treatment of musculoskeletal diseases. Despite all the effort, there is still little evidence that the use of MSCs is effective in musculoskeletal tissue repair. The reasons are manifold, one being the lack of control of a cell's final differentiation. For example, the formation of mechanically inferior fibrous cartilage, instead of hyaline, is one the most common outcomes for articular cartilage tissue engineering [1]. Moreover, the extensive ex vivo manipulation required to obtain large quantities of cells may alter their phenotype and response [2]. Thus, there is a strong need for a better understanding of the underlying molecular mechanisms in order to achieve an efficient differentiation. Besides the genes coding for 
lineage-specific proteins, such as transcription factors, surface receptors, or matrix proteins, cellular processes comprise a variety of different non-coding RNAs (ncRNA) which have regulatory roles and actively participate in lineage specification. The study of ncRNA is therefore of utmost importance to understand the molecular mechanisms of differentiation and how to tune their regulation to be able to build and replace tissues.

The most studied type of ncRNA are microRNAs (miRNA), and their role in stem cell maintenance and differentiation has been investigated [3-5]. A related class of small ncRNA is represented by piwi-interacting RNA (piRNA). piRNA associates with the Piwi subfamily of Argonaute proteins, protecting genome integrity of germline cells by silencing transposable elements through the formation of RNA-induced silencing complexes with Piwi proteins, also known as piRISC [6,7]. Accordingly, their expression has been identified in testis [8], ovary [9], and epididymis [10]. Nonetheless, there is a growing body of evidence that piRNAs also possess important regulatory functions in somatic and cancer cells [7,11-18].

Circular RNA (circRNA) represents a relatively newly recognized class of long ncRNA. Even though their existence has been long acknowledged, circular forms of RNA were thought to merely represent splicing errors with no biological function. Through the advancement of next generation sequencing, which has allowed the rise in RNA sequencing from diverse samples, circRNAs are now recognized to have distinct biogenesis and to regulate gene expression and biological processes through different mechanisms [19,20], with some miRNA-sponging circRNAs identified [21-26]. Moreover, since circRNAs derive from precursor mRNA, they are believed to influence the transcription and/or translation of the linear, protein-coding form [20].

In any case, the role of circRNA in different biological processes is becoming more and more evident. Up to now, a few publications have reported the expression and possible functions of circRNA in MSCs from different organisms, tissue sources, and experimental settings [27-32]. circRNA were differentially expressed in osteogenic differentiation of rat bone marrow MSCs engineered with estrogen receptor $\beta$-targeting shRNA [33]. In human cells, the involvement of circRNAs in osteogenic differentiation of periodontal ligament stem cells [34-36] or maxillary sinus membrane stem cells [37] was reported. One study focused on the osteogenic differentiation of bone marrow stem cells [38]. A map of circRNA expression in clinically relevant tissues, including MSCs and differentiated cells, was also suggested [39] but, until now, there is a paucity of data regarding differential circRNA expression during osteogenic and chondrogenic differentiation of human bone marrow MSCs.

The aim of the present study is to identify differential expression of circRNA, miRNA, and piRNA after lineage commitment towards osteo- and chondrogenesis. Based on previous work highlighting the importance of early events during differentiation, we investigated after day 7 of initiation of differentiation induction. Thus, human MSCs were maintained for 7 days in either osteogenic or chondrogenic medium with relative controls, and RNA sequencing or RNA hybridization arrays were performed. We then identified and validated several differentially regulated circRNA, miRNA, and piRNA, and revealed for some genes the influence of dexamethasone.

\section{Materials and Methods}

\subsection{Cell Isolation and Culture}

MSCs were isolated from human bone marrow, as previously described [40]. The samples were obtained with full ethical approval (Bern Req-2016-00141). Cells from a total of 16 donors were used (11 M/5 F; age mean 60 years; age range 33-80). Cells were cultured maintaining an initial cell density of $3 \times 10^{3}$ cells $/ \mathrm{cm}^{2}$ and grown until passage 2 (p2) in Minimum Essential Medium Eagle-alpha modification ( $\alpha$-MEM, Gibco, Thermo Fisher, Zürich, Switzerland) with the addition of $10 \%$ MSC-qualified FBS (Pan-Biotech, Aidenbach, Germany), $100 \mathrm{U} / \mathrm{mL}$ penicillin, $100 \mu \mathrm{g} / \mathrm{mL}$ streptomycin (Gibco) and $5 \mathrm{ng} / \mathrm{mL}$ basic fibroblast growth factor (bFGF, Fitzgerald Industries International, Acton, 
MA, USA). Cultures were kept in a $37^{\circ} \mathrm{C} / 5 \% \mathrm{CO}_{2}$ humidified atmosphere and the medium was refreshed every second day.

For initial RNA sequencing and hybridization arrays, MSCs from three donors were used. Cells were profiled for standard MSC markers with flow cytometry, as previously described [41]. For further validation, MSCs from 6 additional donors for osteogenic differentiation and chondrogenic differentiation were isolated and differentiated following the same procedure (final $n=9$ ). At p3, cells were induced to either osteo- or chondrogenic differentiation or cultured under control conditions.

For osteogenic differentiation, cells were seeded at a density of $1.5 \times 10^{4}$ cells $/ \mathrm{cm}^{2}$ in 6 -well plates. After overnight cell attachment, the medium was changed: control (CRL monolayer) samples were cultured in Dulbecco's Modified Eagle Medium (DMEM) $1 \mathrm{~g} / \mathrm{L}$ glucose (Gibco), 10\% heat-inactivated FBS (Gibco), $100 \mathrm{U} / \mathrm{mL}$ penicillin and $100 \mu \mathrm{g} / \mathrm{mL}$ streptomycin (Gibco). Osteogenic differentiation was induced by the addition of $50 \mu \mathrm{g} / \mathrm{mL}$ ascorbic acid 2-phosphate, $5 \mathrm{mM} \beta$-glycerol phosphate, and $10 \mathrm{nM}$ dexamethasone (all from Sigma-Aldrich) to the control medium. Samples were prepared in triplicate for each donor and condition.

For chondrogenic differentiation, cells were seeded into pellet culture, using $2 \times 10^{5}$ cells/pellet. Cells were directly seeded into either control (CRL pellet) or chondrogenic medium. Control medium was composed of DMEM $4.5 \mathrm{~g} / \mathrm{L}$ glucose, $100 \mathrm{U} / \mathrm{mL}$ penicillin, $100 \mu \mathrm{g} / \mathrm{mL}$ streptomycin, $1 \%$ Corning ITS+ Premix Universal Culture Supplement, and 1\% non-essential amino acids (NEAA). Chondrogenic medium was prepared from control medium with the addition of $50 \mu \mathrm{g} / \mathrm{mL}$ ascorbic acid 2-phosphate, $100 \mathrm{nM}$ dexamethasone, and $10 \mathrm{ng} / \mathrm{mL}$ TGF- $\beta 1$ (Fitzgerald Industries). The medium was refreshed every second day to keep stable levels of differentiation factors in the media and samples were collected at day 7 for RNA isolation.

Moreover, cultures were maintained up to day 21 for assessing final differentiation outcomes (Alizarin Red staining for osteogenic differentiation and Safranin-O/Fast Green staining on cryosections for chondrogenic differentiation). The RNA samples derived from those three donors were not used for sequencing but for validation purposes only. A summary of donor cohorts used for all experiments is reported in Table S1.

\subsection{RNA Isolation}

Total RNA was isolated from day 7 control (monolayer), day 7 control (pellet), day 7 osteogenic differentiation (OSTEO), and day 7 chondrogenic differentiation (CHONDRO). For control (monolayer) and OSTEO samples, RNA was isolated from 1 well in triplicate for each donor. For control (pellet) and CHONDRO samples, 4 pellets were pooled in one sample and three samples were collected for each condition. Total RNA was isolated using standard TRIreagent (Molecular Research Center Inc., Cincinnati, OH, USA) extraction with 1-Bromo-3-chloropropane (Sigma-Aldrich, St. Louis, MO, USA). After phase separation, RNA was precipitated from the aqueous phase with the addition of 2-propanol (Sigma-Aldrich) with an overnight incubation at $-20^{\circ} \mathrm{C}$ to improve the recovery of small RNA species. Total RNA concentration was measured with NanoDrop 1000 (Thermo Fisher) and purity was assessed by evaluation of the A260/280 and A260/230 ratios.

\subsection{RNA Sequencing and Hybridization}

Two replicates for each group were selected for sequencing ( $n=24$ samples). Two $\mu \mathrm{g}$ of total RNA for each sample was collected and dried in RNAstable ${ }^{\mathrm{TM}}$ tubes (Biomatrica, San Diego, CA, USA) following the manufacturer's instruction. As previously described [42], samples were sent to ArrayStar (Rockville, MD, USA) for library generation and sequencing and RNA microarray hybridization.

Libraries for RNAseq were denatured as single-stranded DNA molecules, captured on Illumina flow cells, amplified in situ as clusters, and sequenced for 51 cycles on an Illumina NextSeq500 system per the manufacturer's instructions.

For miRNA, the Solexa CHASTITY quantity filtered reads were harvested after sequencing as clean reads. The adaptor sequences were trimmed with cutadapt and the adaptor-trimmed reads ( $\geq 15 \mathrm{nt})$ 
were left. miRDeep2 software was used to quantify known miRNA and predict the novel miRNAs. The CPM value for miRNA and the differentially expressed miRNA were calculated and filtered with $R$ package edgeR. Fold change (cutoff 1.5), $p$-value (0.05), and CPM (1 mean in one group) were used for filtering differentially expressed miRNAs. Hierarchical clustering was performed. miRNA target prediction was performed by targetscan (www.targetscan.org) and miRDB (www.mirdb.org), then the GO and KEGG pathway analyses were performed based on the top 10 differentially expressed miRNAs.

For piRNA, the quality of sequencing was examined by FastQC software (https://www. bioinformatics.babraham.ac.uk/projects/fastqc/) and the trimmed reads (that passed Illumina quality filter, trimmed 3'-adaptor bases by cutadapt) were aligned to piRBase (www.pirbase.org), a manually curated database for human piRNA [43,44], using NovoAlign software (v2.07.11, Novocraft Technologies Sdn Bhd, Selangor, Malaysia). The maximum mismatch of $\leq 2$ reads were kept. The expression profiling and differential expression of piRNAs were calculated based on normalized TPM. Hierarchical clustering, scatter plots, and classification analysis were performed with the differentially expressed piRNAs in R or Perl environment for statistical computing and graphics. piRNA annotation and references were gathered from piRBase.

For circRNAs, samples were digested with RNase R (Epicentre Inc., Madison, WI, USA) for enrichment in circRNA content, which was then amplified and transcribed into fluorescent cRNA utilizing a random priming method (Arraystar Super RNA Labeling Kit; Arraystar). The labeled cRNAs were hybridized onto the Arraystar Human circRNA Array V2 $(8 \times 15 \mathrm{~K}$, Arraystar) and the arrays were scanned with an Agilent Scanner G2505C. Image analysis was performed with Agilent Feature Extraction software (version 11.0.1.1, Agilent Technologies Inc. Santa Clara, CA, USA). Quantile normalization and subsequent data processing were performed using the R software limma package [45]. Differentially expressed circRNAs with statistical significance between two groups were identified through Volcano Plot filtering. Hierarchical clustering was performed to show circRNA expression patterns among samples.

Quality controls have been performed by the company at key steps to ensure data quality. RNA sample quality control was carried out using denaturing agarose gel electrophoresis to check for RNA integrity and gDNA contamination. All total RNA samples had intense, sharp, and well-defined $28 \mathrm{~S}$ and $18 \mathrm{~S}$ ribosomal RNA bands, indicating minimal RNA degradation. DNA contamination as a high molecular weight smear or band was absent. For RNAseq, the quality of the sequencing libraries was determined for size distribution and library DNA concentration by an Agilent 2100 Bioanalyzer using the Agilent DNA 1000 chip kit (Agilent Technologies Inc., part \#5067-1504). The sequencing read quality of each sample was analyzed by a Q Score plot, with a Q30 above $90 \%$ for all the samples. For arrays, the cRNA yield for each sample was $>1.65 \mu \mathrm{g}$ and the labeling specific activity was $>9.0$ pmol Cy3 dye per $\mu \mathrm{g}$ cRNA, which were all above the technical QC specifications. The microarray raw scan data all passed spot finding, spatial distribution of outliers, signal statistics, and control stats criteria.

\subsection{RT-qPCR for Validation of Gene Expression from Total RNA and Linear RNA-Depleted Samples}

For total gene expression, cDNA was synthesized using TaqMan Reverse Transcription reagents (Applied Biosystems, Foster City, CA, USA) from 500 ng of total RNA, following the manufacturer's instructions. The expression of protein-coding linear transcripts, corresponding to the circRNA with differential expression in our dataset, was assessed by real-time PCR. Also, differentiation markers were analyzed, such as RUNX2/SOX9 and ALPL or SOX9, COL2A1, and ACAN in osteogenic and chondrogenic differentiation, respectively. Amplification of target genes was achieved using TaqMan Gene Expression Master Mix (Applied Biosystems) in a QuantStudio 6 Flex real-time PCR system (Applied Biosystems) employing the following protocol: $2 \mathrm{~min}$ at $50{ }^{\circ} \mathrm{C} ; 10 \mathrm{~min}$ at $95^{\circ} \mathrm{C} ; 40$ cycles of $15 \mathrm{sec}$ at $95^{\circ} \mathrm{C}, 1 \mathrm{~min}$ at $60^{\circ} \mathrm{C}$. The details about the assays used are collected in Table S2. The genes were tested using the TaqMan gene expression assay (Thermo Fisher), with the exception of RPLPO (reference gene), ACAN, COL1A1, COL2A1, and RUNX2, whose sequences were synthesized 
by Microsynth AG (Balgach, Switzerland). Results of gene expression were expressed as $2^{-\Delta C t}$, with RPLP0 used as a reference gene.

To evaluate gene expression in linear RNA-depleted samples, $1 \mu \mathrm{g}$ of total RNA was treated with RNase $\mathrm{R}$ for $2 \mathrm{~h}$ at $37^{\circ} \mathrm{C}$, immediately followed by the cDNA synthesis described above. The gene expression levels of RPLP0, FKBP5, ZEB1, FADS2, and SMYD3 were assessed using the same protocols described above.

\subsection{Validation of Dexamethasone-Dependent Targets}

In order to understand if the expression of common differentially expressed circRNA in osteoand chondrogenesis could be ascribable to the use of dexamethasone only, independently from the differentiation pathway undertaken, we prepared cell cultures of four additional donors. MSCs were isolated and expanded as described above. After expansion, cells at p3 were seeded into monolayer or pellet culture, as described earlier for controls for osteo- and chondrogenic differentiation. The cells were either maintained in control media or with the addition of $10 \mathrm{nM}$ (in case of monolayer culture) or $100 \mathrm{nM}$ dexamethasone (for pellet culture) in order to reflect the different dosage used previously for the two differentiation protocols. Moreover, additional groups containing $10 \mathrm{nM}$ or $100 \mathrm{nM}$ of the selective nonsteroidal glucocorticoid receptor agonist (+)-ZK216348 (Axon Medchem, Groningen, the Netherlands) were also included to identify whether the mechanism of action observed for dexamethasone could be attributed to transactivation or transrepression pathway. Cells were maintained in culture for 7 days, and then samples were collected for RNA isolation. Gene expression analysis of $F K B P 5, F A D S 2, Z E B 1$, and SMYD3 was performed as described above.

\subsection{Validation of miRNA and piRNA Expression}

The expression of a selection of miRNA and piRNA was validated in the original set of samples via qPCR analysis. cDNA synthesis was performed with a miRCURY LNA RT Kit (Qiagen, Hilden, Germany), using $10 \mathrm{ng}$ of starting RNA according to the manufacturer's instructions. After reverse transcription, qPCR was performed using assays specific for the following miRNA or piRNA: hsa-let-7a-5p, hsa-miR-21-5p, hsa-let-7i-5p, hsa-miR-5690, hsa-miR-125b-5p, hsa-miR-1246, piR-hsa-20757 (DQ590548), piR-hsa-23209 (DQ592931), piR-hsa-23210 (DQ592932), piR-hsa-2107 (DQ571813), and piR-hsa-24672 (DQ594453) (all from Qiagen). The cycling conditions were set as follows: $2 \mathrm{~min}$ at $95^{\circ} \mathrm{C} ; 40$ cycles of $10 \mathrm{sec}$ at $95^{\circ} \mathrm{C}$, and $60 \mathrm{sec}$ at $56^{\circ} \mathrm{C}$. The protocol was concluded by a melt-curve analysis to check for amplicon specificity. Then, hsa-let-7a-5p was used for the normalization of miRNA, which was differentially expressed in osteogenic differentiation, while hsa-miR-21-5p was used for normalization of miRNA in chondrogenic differentiation. In our set of samples, those two miRNAs resulted in the most stable in expression among a panel that also included hsa-miR-199a-3p, hsa-let-7f-5p, hsa-miR-7e-5p, and hsa-miR-100-5p. For piRNA, it was not possible to identify any suitable endogenous control. For this reason, the results were expressed as $2^{-\mathrm{Ct}}$ and values compared between differentiation vs. undifferentiated controls. This provides only an initial indicative data to further validate those targets and to undertake a path leading to the identification of "housekeeping" piRNA and a proper qPCR analysis of piRNA.

\subsection{Statistical Analysis}

GraphPad Prism v.8 (GraphPad Software, San Diego, CA, USA) was used for statistical analysis. A two-tailed ratio paired Student's $t$-test was used to compare expression levels between day 7 differentiation vs. its relative control. For the validation of dexamethasone-dependent targets in monolayer or pellet cultures, the results were analyzed with a two-way ANOVA and Tukey's multiple comparison test to assess the effect of culture type, treatment, and their interaction on gene expression. 


\section{Results}

\subsection{MSC Immunophenotype and Osteo/Chondrogenic Differentiation Potential}

As expected, MSCs showed the classical surface CD marker expression, with positivity for CD44, CD73, CD90, and CD105, while being negative for CD11b, CD19, CD34, and CD45. Results are summarized in Figure S1A,B.

Figure S1 also shows the differentiation potential of MSCs towards the osteogenic and chondrogenic lineages, with Alizarin Red and Safranin-O staining, respectively. Moreover, analysis of day 7 gene expression shows the regulation of the RUNX2/SOX9 ratio [46] and ALPL expression in early osteogenesis, and upregulation of $S O X 9, C O L 2 A 1$, and $A C A N$ in early chondrogenic differentiation.

\subsection{Differential Expression of circRNA in Early Osteo- and Chondrogenesis}

Bioinformatic analysis of hybridization arrays revealed 21 upregulated circRNAs and 21 downregulated in day 7 osteogenic differentiation compared to day 7 control (monolayer), while 130 were upregulated and 97 downregulated during chondrogenic differentiation (Figure S2). Tables 1 and 2 show a selection of the differentially expressed circRNA in osteogenic and in chondrogenic differentiation, respectively. The full list can be found in Tables S3 and S4. The data are available in NCBI's Gene Expression Omnibus [47] and are accessible through GEO series accession number GSE135588 (https://www.ncbi.nlm.nih.gov/geo/query/acc.cgi?acc=GSE135588), subseries GSE135883 (https://www.ncbi.nlm.nih.gov/geo/query/acc.cgi?acc=GSE135883).

Table 1. Selection of differentially-expressed circRNA in osteogenic differentiation. CircRNAs are sorted and ranked by fold change. The results of hybridization arrays identified 21 upregulated and 21 downregulated circular RNAs in osteogenic differentiation vs. undifferentiated control.

\begin{tabular}{|c|c|c|c|c|c|c|c|c|}
\hline Rank & probeID & P-value & FDR & FC (abs) & Reg & circRNA & $\begin{array}{c}\text { Gene } \\
\text { Symbol }\end{array}$ & $\begin{array}{l}\text { miRNA Response } \\
\text { Elements }\end{array}$ \\
\hline$\# 1$ & ASCRP3005562 & 6.047E-08 & 0.000720802 & 5.4280811 & up & hsa_circRNA_104101 & FKBP5 & $\begin{array}{l}\text { hsa-miR-1468-5p } \\
\text { hsa-miR-642a-5p } \\
\text { hsa-miR-561-5p } \\
\text { hsa-miR-29b-1-5p } \\
\text { hsa-miR-708-5p }\end{array}$ \\
\hline$\# 2$ & ASCRP3000836 & 1.1812E-06 & 0.007039952 & 3.9089404 & up & hsa_circRNA_002161 & FKBP5 & $\begin{array}{l}\text { hsa-miR-619-5p } \\
\text { hsa-miR-20b-3p } \\
\text { hsa-miR-367-3p } \\
\text { hsa-miR-153-5p } \\
\text { hsa-miR-665 }\end{array}$ \\
\hline$\# 3$ & ASCRP3000835 & $8.88526 \mathrm{E}-06$ & 0.02118246 & 3.3616827 & up & hsa_circRNA_076155 & FKBP5 & $\begin{array}{l}\text { hsa-miR-6845-3p } \\
\text { hsa-miR-1468-5p } \\
\text { hsa-miR-642a-5p } \\
\text { hsa-miR-6834-3p } \\
\text { hsa-miR-561-5p }\end{array}$ \\
\hline$\# 4$ & ASCRP3000434 & 0.004935888 & 0.960907885 & 2.8301448 & up & hsa_circRNA_022382 & FADS2 & $\begin{array}{c}\text { hsa-miR-5586-5p } \\
\text { hsa-miR-4726-5p } \\
\text { hsa-miR-4640-5p } \\
\text { hsa-miR-3138 } \\
\text { hsa-miR-8080 }\end{array}$ \\
\hline$\# 5$ & ASCRP3003129 & 0.019088529 & 0.960907885 & 2.8255694 & up & hsa_circRNA_100833 & FADS2 & $\begin{array}{c}\text { hsa-miR-765 } \\
\text { hsa-miR-495-3p } \\
\text { hsa-miR-665 } \\
\text { hsa-miR-193b-5p } \\
\text { hsa-miR-124-5p }\end{array}$ \\
\hline \#6 & ASCRP3001707 & $1.86216 \mathrm{E}-06$ & 0.007398982 & 2.6965752 & up & hsa_circRNA_406763 & FKBP5 & $\begin{array}{c}\text { hsa-miR-1273g-3p } \\
\text { hsa-miR-1285-3p } \\
\text { hsa-miR-619-5p } \\
\text { hsa-miR-1183 } \\
\text { hsa-miR-512-5p }\end{array}$ \\
\hline
\end{tabular}


Table 1. Cont.

\begin{tabular}{|c|c|c|c|c|c|c|c|c|}
\hline Rank & probeID & P-value & FDR & FC (abs) & Reg & circRNA & $\begin{array}{c}\text { Gene } \\
\text { Symbol }\end{array}$ & $\begin{array}{l}\text { miRNA Response } \\
\text { Elements }\end{array}$ \\
\hline$\# 7$ & ASCRP3013118 & 0.003143209 & 0.960907885 & 2.304461 & up & hsa_circRNA_100834 & FADS2 & $\begin{array}{c}\text { hsa-miR-873-5p } \\
\text { hsa-miR-23b-5p } \\
\text { hsa-miR-181a-2-3p } \\
\text { hsa-miR-93-3p } \\
\text { hsa-miR-299-3p }\end{array}$ \\
\hline$\# 9$ & ASCRP3001839 & 0.000150493 & 0.172024477 & 2.0442825 & up & hsa_circRNA_406308 & COL8A1 & $\begin{array}{c}\text { hsa-miR-153-5p } \\
\text { hsa-miR-126-5p } \\
\text { hsa-miR-1277-5p } \\
\text { hsa-miR-548az-5p } \\
\text { hsa-miR-3607-3p }\end{array}$ \\
\hline$\# 12$ & ASCRP3009465 & 0.007384491 & 0.960907885 & 1.9128242 & up & hsa_circRNA_057186 & AGPS & $\begin{array}{l}\text { hsa-miR-3938 } \\
\text { hsa-miR-942-5p } \\
\text { hsa-miR-3935 } \\
\text { hsa-miR-646 } \\
\text { hsa-miR-4753-3p }\end{array}$ \\
\hline$\# 13$ & ASCRP3007511 & 0.005784275 & 0.960907885 & 1.8653692 & up & hsa_circRNA_100832 & FADS1 & $\begin{array}{c}\text { hsa-miR-218-1-3p } \\
\text { hsa-miR-193a-5p } \\
\text { hsa-miR-764 } \\
\text { hsa-miR-876-3p } \\
\text { hsa-miR-138-5p }\end{array}$ \\
\hline$\# 15$ & ASCRP3002616 & 0.035838981 & 0.960907885 & 1.6842185 & up & hsa_circRNA_104864 & LPAR1 & $\begin{array}{c}\text { hsa-miR-7-5p } \\
\text { hsa-miR-588 } \\
\text { hsa-miR-135a-3p } \\
\text { hsa-miR-608 } \\
\text { hsa-miR-140-3p }\end{array}$ \\
\hline$\# 16$ & ASCRP3003960 & 0.009707576 & 0.960907885 & 1.679094 & up & hsa_circRNA_402206 & LTBP1 & $\begin{array}{l}\text { hsa-miR-432-5p } \\
\text { hsa-miR-6797-3p } \\
\text { hsa-miR-3127-3p } \\
\text { hsa-miR-6804-5p } \\
\text { hsa-miR-18a-3p }\end{array}$ \\
\hline$\# 17$ & ASCRP3003038 & 0.011416289 & 0.960907885 & 1.6747001 & up & hsa_circRNA_000782 & ZEB1 & $\begin{array}{l}\text { hsa-miR-141-3p } \\
\text { hsa-miR-200a-3p } \\
\text { hsa-miR-148a-5p } \\
\text { hsa-miR-136-5p } \\
\text { hsa-miR-494-5p }\end{array}$ \\
\hline$\# 20$ & ASCRP3001742 & 0.044814485 & 0.960907885 & 1.5884727 & up & hsa_circRNA_100582 & ZEB1 & $\begin{array}{l}\text { hsa-miR-141-3p } \\
\text { hsa-miR-200a-3p } \\
\text { hsa-miR-148a-5p } \\
\text { hsa-miR-452-3p } \\
\text { hsa-miR-877-3p }\end{array}$ \\
\hline$\# 1$ & ASCRP3007208 & 0.002787677 & 0.923030978 & 0.4292865 & down & hsa_circRNA_100512 & SMYD3 & $\begin{array}{l}\text { hsa-miR-182-5p } \\
\text { hsa-miR-181a-5p } \\
\text { hsa-miR-532-3p } \\
\text { hsa-miR-1224-3p } \\
\text { hsa-miR-181b-5p }\end{array}$ \\
\hline
\end{tabular}


Table 1. Cont

\begin{tabular}{|c|c|c|c|c|c|c|c|}
\hline Rank & probeID & P-value & FDR & FC (abs) & circRNA & $\begin{array}{c}\text { Gene } \\
\text { Symbol }\end{array}$ & $\begin{array}{l}\text { miRNA Response } \\
\text { Elements }\end{array}$ \\
\hline \#3 & ASCRP3004046 & 0.000140327 & 0.172024477 & 0.4904122 & down hsa_circRNA_100835 & BSCL2 & $\begin{array}{c}\text { hsa-miR-646 } \\
\text { hsa-miR-199b-5p } \\
\text { hsa-let-7g-5p } \\
\text { hsa-let-7e-5p } \\
\text { hsa-miR-658 }\end{array}$ \\
\hline \#6 & ASCRP3012578 & 7.30204E-05 & 0.108800441 & 0.5413913 & down hsa_circRNA_103729 & PDE5A & $\begin{array}{l}\text { hsa-miR-670-3p } \\
\text { hsa-miR-583 } \\
\text { hsa-miR-455-3p } \\
\text { hsa-miR-510-3p } \\
\text { hsa-miR-500a-5p }\end{array}$ \\
\hline$\# 7$ & ASCRP3008231 & 0.009384685 & 0.960907885 & 0.5464973 & down hsa_circRNA_100509 & SMYD3 & $\begin{array}{c}\text { hsa-miR-516b-3p } \\
\text { hsa-miR-516a-3p } \\
\text { hsa-miR-671-5p } \\
\text { hsa-miR-425-3p } \\
\text { hsa-miR-584-5p }\end{array}$ \\
\hline$\# 8$ & ASCRP3007154 & 0.004585789 & 0.960907885 & 0.5603480 & down hsa_circRNA_100510 & SMYD3 & $\begin{array}{l}\text { hsa-miR-516a-3p } \\
\text { hsa-miR-516b-3p } \\
\text { hsa-miR-182-5p } \\
\text { hsa-miR-181a-5p } \\
\text { hsa-miR-362-5p }\end{array}$ \\
\hline$\# 9$ & ASCRP3001523 & 0.002025898 & 0.832713912 & 0.5671141 & down hsa_circRNA_103415 & FOXP1 & $\begin{array}{l}\text { hsa-miR-370-3p } \\
\text { hsa-miR-558 } \\
\text { hsa-miR-127-5p } \\
\text { hsa-miR-93-3p } \\
\text { hsa-miR-17-3p }\end{array}$ \\
\hline$\# 10$ & ASCRP3009267 & 0.000205329 & 0.180247633 & 0.5766464 & down hsa_circRNA_102854 & PDK1 & $\begin{array}{l}\text { hsa-miR-362-5p } \\
\text { hsa-miR-500a-5p } \\
\text { hsa-miR-30a-5p } \\
\text { hsa-miR-30e-5p } \\
\text { hsa-miR-21-3p }\end{array}$ \\
\hline$\# 14$ & ASCRP3003982 & $2.29715 \mathrm{E}-05$ & 0.045636674 & 0.6169628 & down hsa_circRNA_406933 & PDE1C & $\begin{array}{c}\text { hsa-miR-138-5p } \\
\text { hsa-miR-1248 } \\
\text { hsa-miR-3653-5p } \\
\text { hsa-miR-6755-3p } \\
\text { hsa-miR-26b-3p }\end{array}$ \\
\hline$\# 16$ & ASCRP3007600 & 0.009304848 & 0.960907885 & 0.6298330 & down hsa_circRNA_103414 & FOXP1 & $\begin{array}{l}\text { hsa-miR-370-3p } \\
\text { hsa-miR-558 } \\
\text { hsa-miR-127-5p } \\
\text { hsa-miR-93-3p } \\
\text { hsa-miR-17-3p }\end{array}$ \\
\hline \#19 & ASCRP3010569 & 0.000767043 & 0.481218738 & 0.6493059 & down hsa_circRNA_102856 & PDK1 & $\begin{array}{c}\text { hsa-miR-637 } \\
\text { hsa-miR-362-5p } \\
\text { hsa-miR-500a-5p } \\
\text { hsa-miR-30a-5p } \\
\text { hsa-miR-511-5p }\end{array}$ \\
\hline \#21 & ASCRP3000965 & 0.001161463 & 0.604800463 & 0.6630723 & down hsa_circRNA_102855 & PDK1 & $\begin{array}{c}\text { hsa-miR-637 } \\
\text { hsa-miR-362-5p } \\
\text { hsa-miR-500a-5p } \\
\text { hsa-miR-30a-5p } \\
\text { hsa-miR-511-5p }\end{array}$ \\
\hline
\end{tabular}


Table 2. Selection of differentially expressed circRNA in chondrogenic differentiation. CircRNAs are sorted and ranked by fold change. The results of hybridization arrays identified 130 upregulated and 197 downregulated circular RNAs in osteogenic differentiation vs. undifferentiated control. The full table, including all the differentially expressed circRNA in chondrogenic differentiation, is available in the supplementary file (Table S4).

\begin{tabular}{|c|c|c|c|c|c|c|c|c|}
\hline Rank & probeID & P-value & FDR & FC (abs) & Reg & circRNA & $\begin{array}{c}\text { Gene } \\
\text { Symbol }\end{array}$ & $\begin{array}{l}\text { miRNA Response } \\
\text { Elements }\end{array}$ \\
\hline$\# 1$ & ASCRP3005562 & $1.63024 \mathrm{E}-06$ & 0.003238743 & 5.3480122 & up & hsa_circRNA_104101 & FKBP5 & $\begin{array}{c}\text { hsa-miR-1468-5p } \\
\text { hsa-miR-642a-5p } \\
\text { hsa-miR-561-5p } \\
\text { hsa-miR-29b-1-5p } \\
\text { hsa-miR-708-5p }\end{array}$ \\
\hline$\# 2$ & ASCRP3000434 & 0.000396713 & 0.055633194 & 4.6683484 & up & hsa_circRNA_022382 & FADS2 & $\begin{array}{l}\text { hsa-miR-5586-5p } \\
\text { hsa-miR-4726-5p } \\
\text { hsa-miR-4640-5p } \\
\text { hsa-miR-3138 } \\
\text { hsa-miR-8080 }\end{array}$ \\
\hline$\# 3$ & ASCRP3000836 & 0.000102233 & 0.031215885 & 4.496583 & up & hsa_circRNA_002161 & FKBP5 & $\begin{array}{l}\text { hsa-miR-619-5p } \\
\text { hsa-miR-20b-3p } \\
\text { hsa-miR-367-3p } \\
\text { hsa-miR-153-5p } \\
\text { hsa-miR-665 }\end{array}$ \\
\hline$\# 4$ & ASCRP3009795 & $1.8396 \mathrm{E}-07$ & 0.001096402 & 3.9770883 & up & hsa_circRNA_081069 & COL1A2 & $\begin{array}{c}\text { hsa-miR-4733-3p } \\
\text { hsa-miR-665 } \\
\text { hsa-miR-5096 } \\
\text { hsa-miR-412-3p } \\
\text { hsa-miR-4459 }\end{array}$ \\
\hline \#6 & ASCRP3006708 & 7.97805E-05 & 0.030676897 & 3.7163892 & up & hsa_circRNA_102121 & COL1A1 & $\begin{array}{l}\text { hsa-miR-412-3p } \\
\text { hsa-miR-214-3p } \\
\text { hsa-miR-194-3p } \\
\text { hsa-miR-761 } \\
\text { hsa-miR-362-5p }\end{array}$ \\
\hline$\# 7$ & ASCRP3003129 & 0.000497582 & 0.061309307 & 3.5929669 & up & hsa_circRNA_100833 & FADS2 & $\begin{array}{l}\text { hsa-miR-765 } \\
\text { hsa-miR-495-3p } \\
\text { hsa-miR-665 } \\
\text { hsa-miR-193b-5p } \\
\text { hsa-miR-124-5p }\end{array}$ \\
\hline$\# 8$ & ASCRP3000835 & 0.000417696 & 0.057894568 & 3.1908719 & up & hsa_circRNA_076155 & FKBP5 & $\begin{array}{l}\text { hsa-miR-6845-3p } \\
\text { hsa-miR-1468-5p } \\
\text { hsa-miR-642a-5p } \\
\text { hsa-miR-6834-3p } \\
\text { hsa-miR-561-5p }\end{array}$ \\
\hline$\# 15$ & ASCRP3002750 & $8.236 \mathrm{E}-07$ & 0.001963462 & 2.7030084 & up & hsa_circRNA_400670 & FGFR2 & $\begin{array}{l}\text { hsa-miR-449c-5p } \\
\text { hsa-miR-885-3p } \\
\text { hsa-miR-216b-3p } \\
\text { hsa-miR-3147 } \\
\text { hsa-miR-4691-3p }\end{array}$ \\
\hline$\# 16$ & ASCRP3009380 & 0.000395625 & 0.055633194 & 2.6823979 & up & hsa_circRNA_400294 & COL11A1 & $\begin{array}{c}\text { hsa-miR-4668-3p } \\
\text { hsa-miR-4659a-3p } \\
\text { hsa-miR-4659b-3p } \\
\text { hsa-miR-2113 } \\
\text { hsa-miR-548aq-3p }\end{array}$ \\
\hline$\# 18$ & ASCRP3004582 & 6.12173E-05 & 0.026061058 & 2.544377 & up & hsa_circRNA_103987 & SPARC & $\begin{array}{l}\text { hsa-miR-194-3p } \\
\text { hsa-miR-22-5p } \\
\text { hsa-miR-342-5p } \\
\text { hsa-miR-328-3p } \\
\text { hsa-miR-30d-3p }\end{array}$ \\
\hline$\# 22$ & ASCRP3013118 & 0.0007731 & 0.075807131 & 2.2866119 & up & hsa_circRNA_100834 & FADS2 & $\begin{array}{c}\text { hsa-miR-873-5p } \\
\text { hsa-miR-23b-5p } \\
\text { hsa-miR-181a-2-3p } \\
\text { hsa-miR-93-3p } \\
\text { hsa-miR-299-3p }\end{array}$ \\
\hline$\# 23$ & ASCRP3001707 & 0.006322882 & 0.219733971 & 2.2821711 & up & hsa_circRNA_406763 & FKBP5 & $\begin{array}{c}\text { hsa-miR-1273g-3p } \\
\text { hsa-miR-1285-3p } \\
\text { hsa-miR-619-5p } \\
\text { hsa-miR-1183 } \\
\text { hsa-miR-512-5p }\end{array}$ \\
\hline
\end{tabular}


Table 2. Cont.

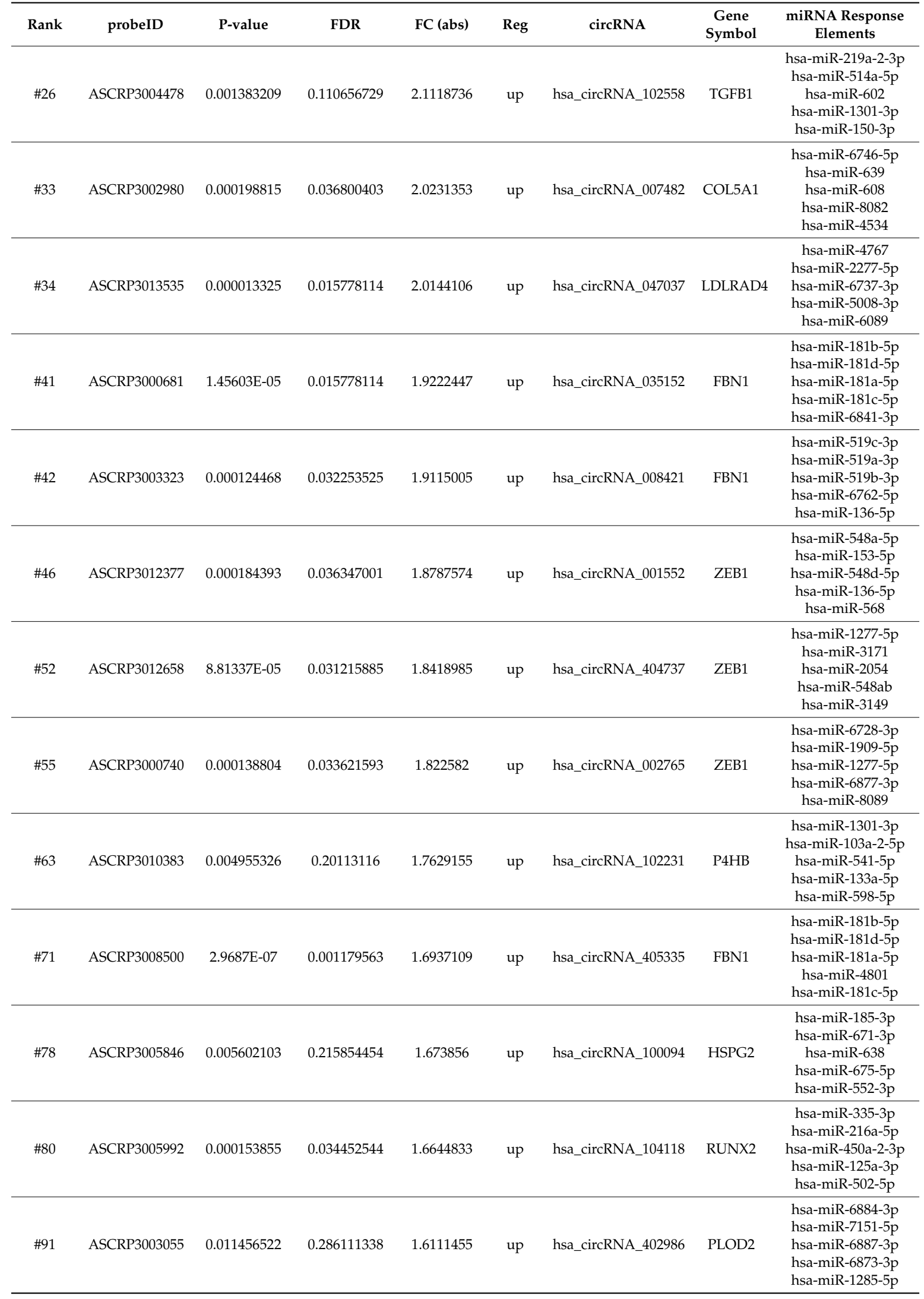


Table 2. Cont

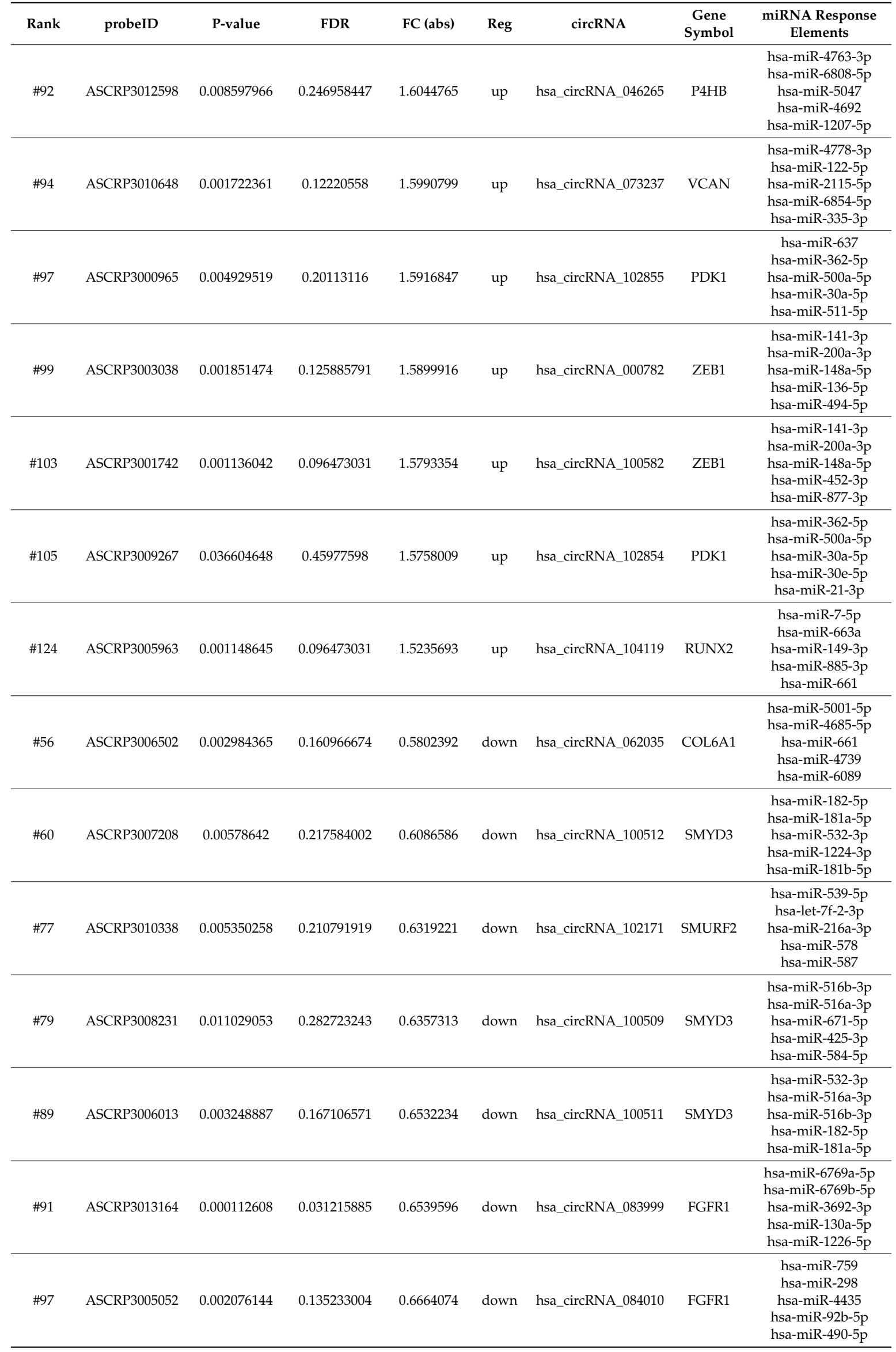


As shown in Table 1 and Table S3, the top seven upregulated circRNA in osteogenic differentiation are derived from the same two genes: FKBP5 (4 circRNA) and FADS2 (3 circRNA). Overall, the 21 upregulated circRNAs are originated from 14 protein-coding genes and 1 long non-coding RNA. The ZEB1 gene also gives origin to 2 circRNA. Downregulated circRNAs in osteogenesis likewise comprise multiple circRNA derived from a single gene, such as SMYD3 $(n=4)$ or PDK1 $(n=3)$, with a total of 12 genes and 1 intergenic sequence originating the 21 downregulated circles.

Similarly, in chondrogenic differentiation (Table 2 and Table S4) many circRNAs share the same precursor gene, such as FKBP5 $(n=3)$, FADS2 $(n=3), Z E B 1(n=5)$, PH4B $(n=2)$, or RUNX2 $(n=2)$ within upregulated circRNAs, or FGFR1 $(n=2)$ and SMYD3 $(n=3)$ among those downregulated. Interestingly, ADAMTS6 is represented with two circRNA, one upregulated and one downregulated in chondrogenic differentiation.

Of note, it was observed that five genes originate circRNA that are differentially expressed in both osteo- and chondrogenesis. In particular, FKBP5, FADS2, and ZEB1 were upregulated and $S M Y D 3$ was downregulated in both, while PDK1 was upregulated in osteo- and downregulated in chondrogenic differentiation. The Venn chart in Figure 1 summarizes the common circRNAs in early osteo- and chondrogenesis.

For validation purposes, we first ranked differentially expressed circRNA based on fold change; then, we selected a panel of species to be validated based mainly on fold change and gene derivation of the circRNA. FDR values were also taken into account, although it was not used as an absolute discriminating factor between including a gene into the validation group or not.

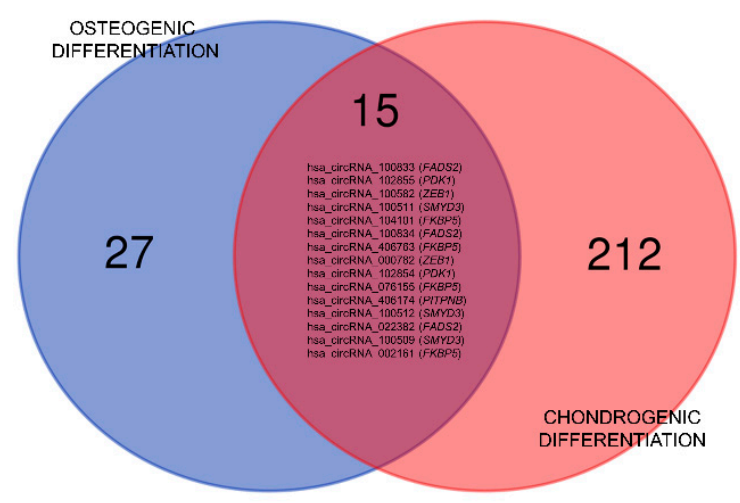

Figure 1. Venn diagram summarizing circRNA differential regulation in osteogenic and in chondrogenic differentiation. The chart was generated with the help of the following online tool: http://bioinformatics. psb.ugent.be/webtools/Venn/. The number of unique elements was 254 (42 for osteogenic and 227 for chondrogenic differentiation).

\subsection{Validation of Gene Expression from Total RNA and Linear RNA-Depleted Samples}

Since circRNAs derive from precursor mRNA and the expression of linear and circular forms is co-regulated [20], we analyzed total gene expression for a selection of circRNAs.

The results shown in Figure 2 focus on the analysis of gene expression for FKBP5, FADS2, ZEB1, and $S M Y D 3$, corresponding to the differentially expressed circRNAs in both osteo-and chondrogenic differentiation. Total gene expression is shown in Figure 2A, confirming their differential regulation in both differentiation cultures, except for ZEB1 in chondrogenic differentiation. The analysis of the same genes in RNaseR treated-derived samples allowed us to evaluate circRNA expression (Figure 2B), with circular FKBP5 and ZEB1 being upregulated in both osteogenic and chondrogenic differentiation, while circular FADS2 was significantly increased in osteogenesis only. Figure $2 \mathrm{C}$ shows the proportion of circular isoforms on total gene expression. In the case of $F A D S 2$, a high percentage of total gene expression is represented by the circular isoforms, especially in chondrogenic differentiation where they account for around $90 \%$ of the total transcript. 


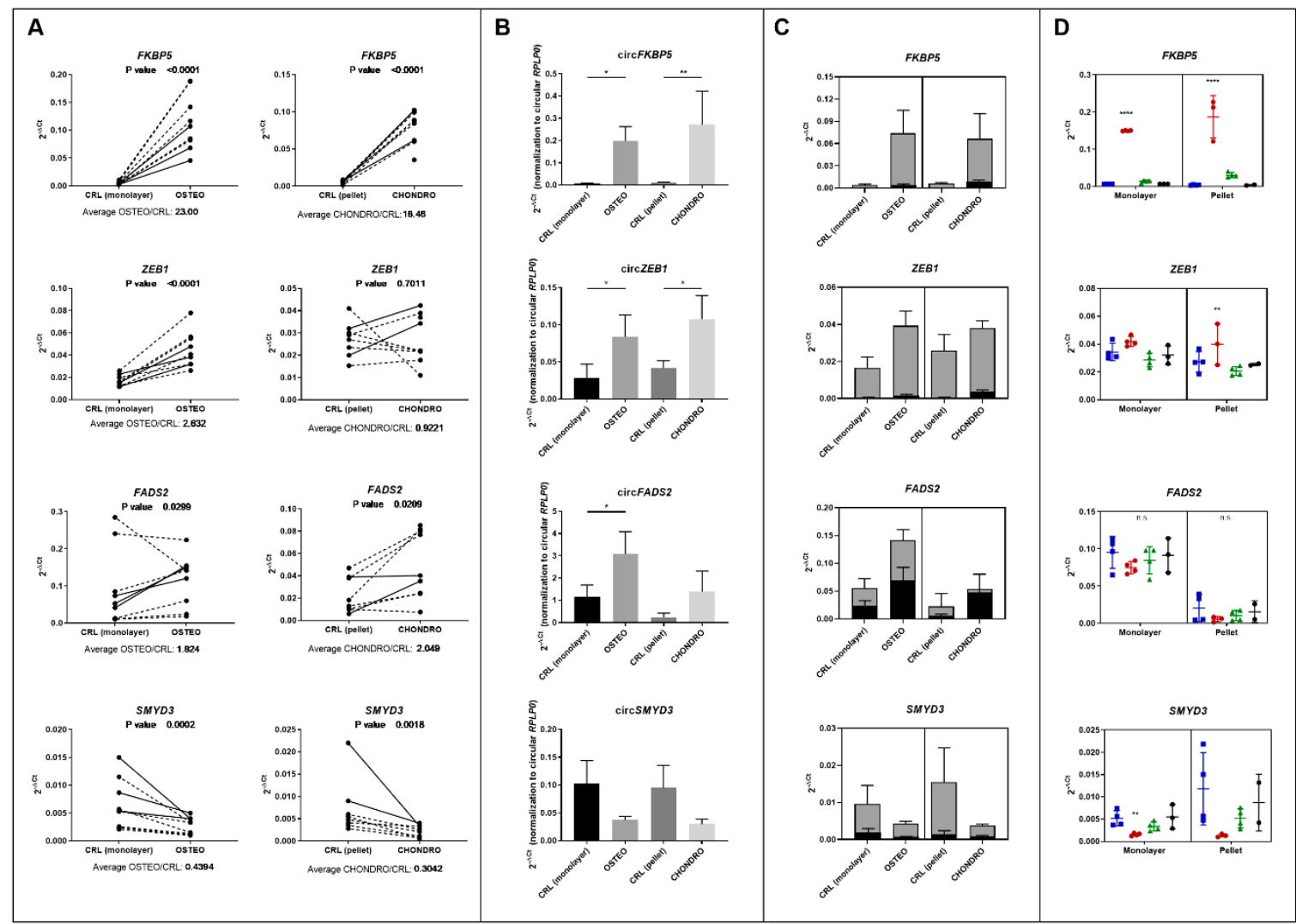

Figure 2. (A) Validation of total gene expression levels $(n=9)$ corresponding to differentially expressed circular RNAs in both osteogenic (left) and chondrogenic differentiation (right). Full lines represent results from the donors used for microarray $(n=3)$, while dashed lines correspond to additional donors tested ( $n=6$ for osteogenic and $n=6$ for chondrogenic differentiation). For each gene of interest (GOI), the results are shown as $2^{-\Delta \mathrm{Ct}}$, where $\Delta \mathrm{Ct}$ is calculated as the difference between GOI and reference gene (RPLPO) Ct values. The $p$-value and the average fold change between day 7 differentiation and day 7 controls are reported for each gene. (B) The expression of the same genes was tested after RNase $\mathrm{R}$ treatment ( $n=3$ donors) to validate the differential expression of the circular RNA. The expression of circular forms of genes was normalized to RPLPO analyzed in RNase R treated samples (circular $R P L P 0)$. (C) Proportion of circular transcripts on overall gene expression. The grey bar indicates the total amount of transcript for each gene, the black bar shows the amount of circular RNA. For this purpose, both circular and total transcripts were normalized to total RPLP0 ( $n=3$ donors). (D) Effect of dexamethasone on the expression of total FKBP5, ZEB1, FADS2, and SMYD3 in monolayer or pellet cultures. Blue bars and symbols: negative control (no treatment); red: dexamethasone treatment (10 nM in monolayer, $100 \mathrm{nM}$ in pellet culture); green: (+)-ZK216348 treatment (10 $\mathrm{nM}$ in monolayer, $100 \mathrm{nM}$ in pellet culture); black: vehicle control (DMSO). $n=4$ donors. *: $p<0.05 ;{ }^{* *}: p<0.01$; $^{* * *}: p<0.0001$.

Moreover, in order to understand if total FKBP5, FADS2, ZEB1, and SMYD3 expression was influenced by dexamethasone, we tested the action of dexamethasone only on either monolayer or pellet control culture, without the addition of any other differentiation agent. In addition, a group treated with the same concentrations of (+)-ZK216348 was included to distinguish between the transactivation or transrepression pathway of the glucocorticoid signaling pathway.

As depicted in Figure 2D, the results showed that FKBP5 was affected only by the treatment type, with a marked upregulation observed for dexamethasone-treated cells both in monolayer and pellet cultures (fold change of 21.4 and 46.75, respectively, in comparison to the negative control), while no effect of (+)-ZK216348 was observed. A trend towards an upregulation of ZEB1 and a downregulation of SMYD3 was also observed, although it reached statistical significance only in pellet culture and in monolayer, respectively $(p<0.01)$. On the contrary, no influence of both dexamethasone 
or (+)-ZK216348 has been observed on FADS2 expression, with only the culture type significantly affecting the levels of gene expression.

\subsection{Validation of Total Gene Expression for Specific Osteo- or Chondrogenesis Targets}

As shown in Figure 3, the differential expression of total COL8A1, LTBP1, MT2A, FBLN1, LPAR1, $B S C L 2, P D E 1 C$, and PDK1 was confirmed by qPCR analysis for osteogenic differentiation, showing the same trend of regulation for the circular, as detected by microarrays, and total transcripts. The only exception was represented by the BSCL2 gene, whose circular transcript was downregulated in osteogenic differentiation, but total gene expression resulted upregulated. The expression of AGPS and TDRD12 did not show differential expression between control and osteogenic differentiation, while $P D E 5 A$ showed a trend towards a downregulation even though the $p$-value remained above 0.05 .

In early chondrogenic commitment, the differential expression of COL1A1, COL1A2, COL5A1, COL6A1, COL11A1, PLOD2, FGFR1, LDLRAD4, SMURF2, and SPARC was validated by qPCR analysis (Figure 4). Total gene expression showed the same direction of regulation as for the circular form, i.e., an upregulated circRNA corresponded to an overall higher expression of the parental gene.

The fold expression between osteogenic or chondrogenic differentiation and the relative controls are reported in Figures 3 and 4.

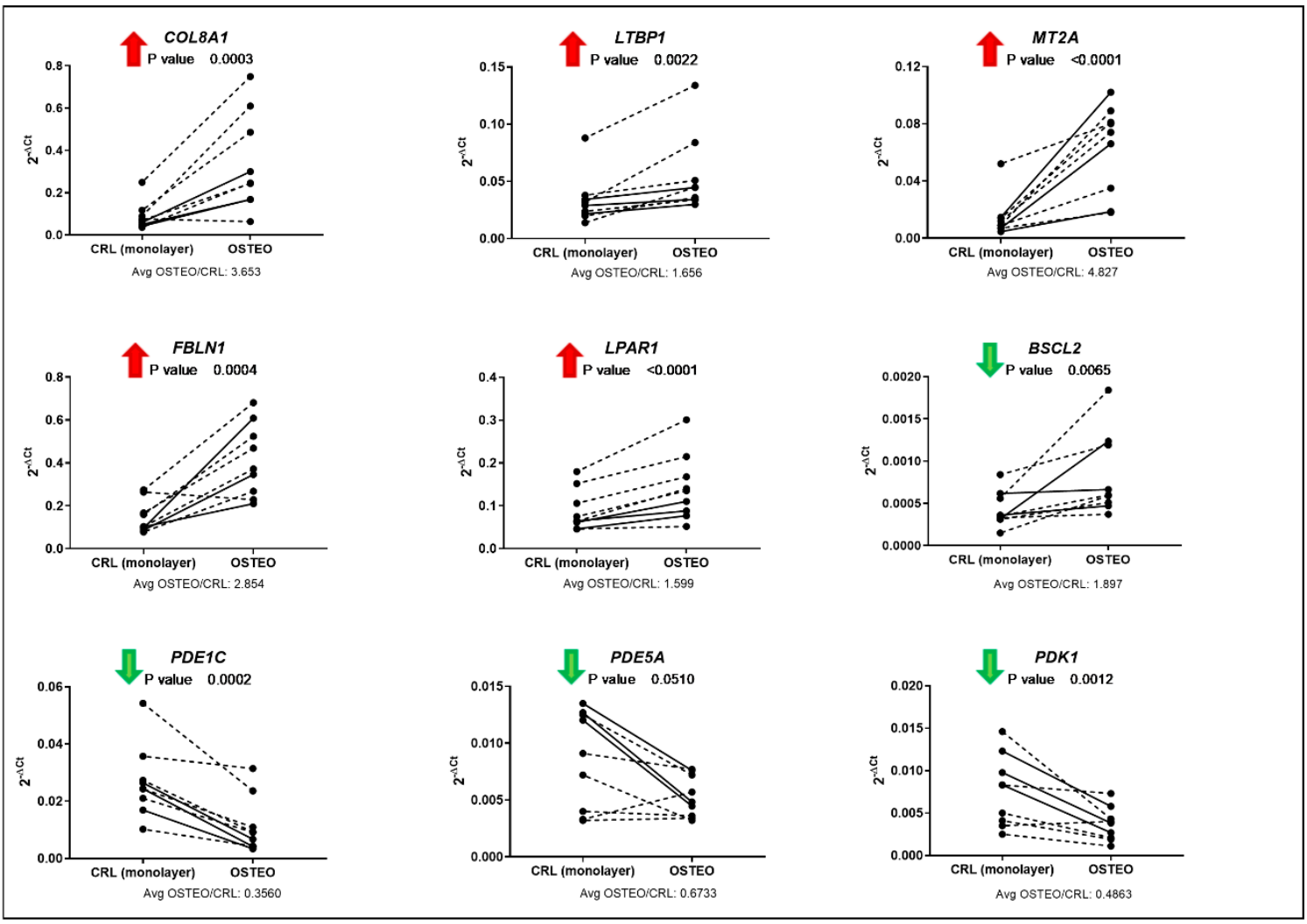

Figure 3. qPCR validation of linear targets corresponding to differentially expressed circular RNAs in osteogenic differentiation, as identified by microarray analysis. Full lines represent results from the same donors used for microarray, while dashed lines correspond to additional donors tested. For each gene of interest (GOI), the results are shown as $2^{-\Delta \mathrm{Ct}}$, where $\Delta \mathrm{Ct}$ is calculated as the difference between GOI and reference gene (RPLPO) Ct values. The $p$-value and the average fold change between day 7 osteogenic differentiation and day 7 control (monolayer) are reported for each gene. The arrow next to the gene symbol indicates if the corresponding circRNA resulted as up- or downregulated from the microarray analysis. 


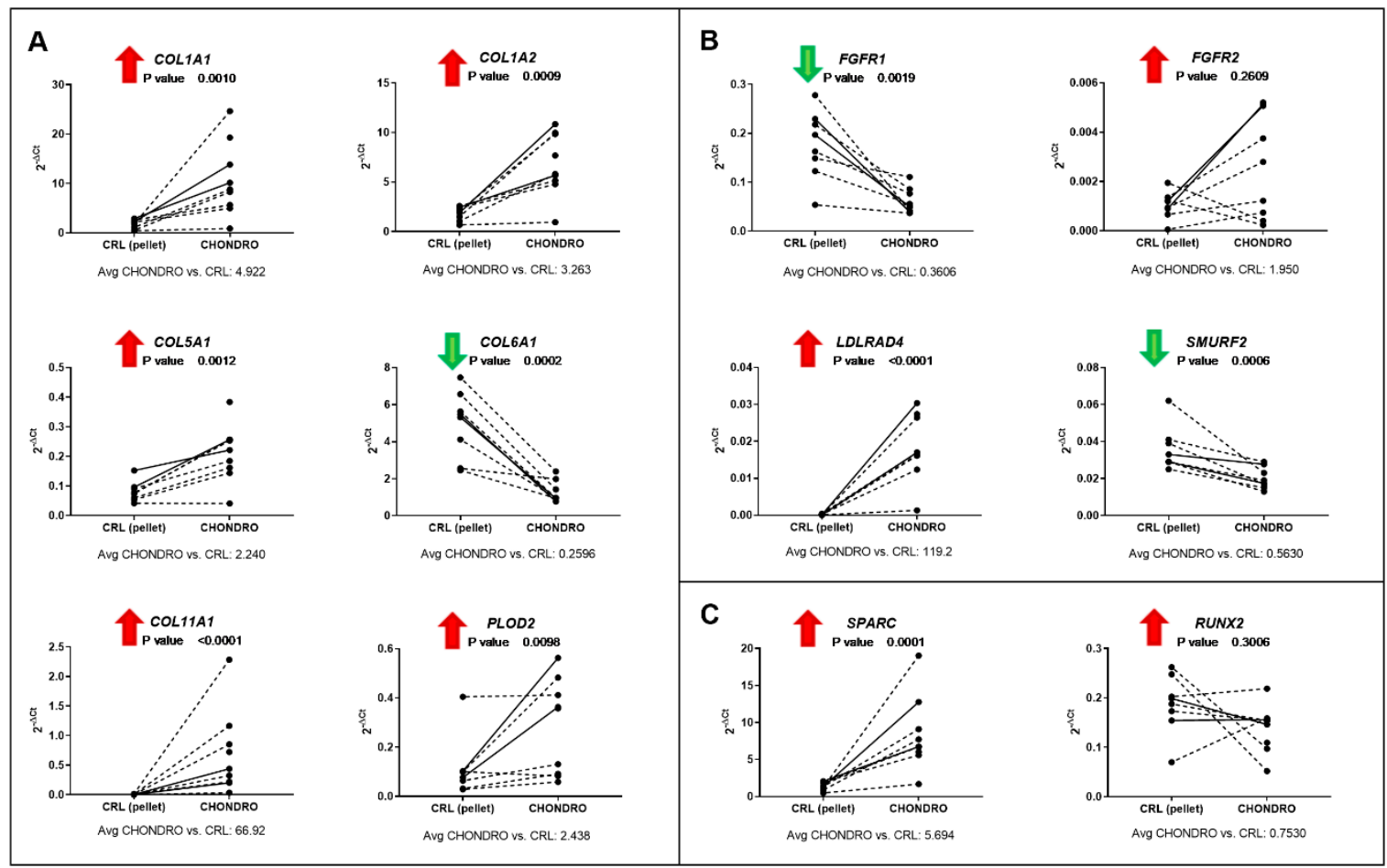

Figure 4. qPCR validation of linear targets corresponding to differentially expressed circular RNAs in chondrogenic differentiation and associated to (A) collagen fibril synthesis; (B) FGF and TGF- $\beta$ signaling pathways; (C) endochondral ossification pathway. Full lines represent results from the same donors used for microarray, while dashed lines correspond to additional donors tested. For each gene of interest (GOI), the results are shown as $2^{-\Delta C t}$, where $\Delta \mathrm{Ct}$ is calculated as the difference between $\mathrm{GOI}$ and reference gene (RPLPO) Ct values. The $p$-value and the average fold change between day 7 chondrogenic differentiation and day 7 control (pellet) expression are reported for each gene. The arrow next to the gene symbol indicates if the corresponding circRNA resulted as up- or downregulated from the microarray analysis.

\subsection{Differential Expression of microRNA in Early Osteo- and Chondrogenesis}

Analysis of RNAseq results identified 47 upregulated and 57 downregulated miRNAs in day 7 osteogenic differentiation compared to control (monolayer). During chondrogenic differentiation, 102 miRNAs were upregulated and 108 downregulated. Figure S3 shows the hierarchical clustering of miRNA expression, while Figure S4 is the volcano plot for the identification of differentially expressed miRNAs. The data are available in GEO series GSE135588 (https://www.ncbi.nlm.nih.gov/geo/query/ acc.cgi?acc=GSE135588), subseries GSE135586 (https://www.ncbi.nlm.nih.gov/geo/query/acc.cgi?acc= GSE135586).

Tables S5 and S6 show the full list of differentially expressed miRNA in osteogenic and in chondrogenic differentiation, respectively, while Figure S5 reports the pathway enrichment analysis for differentially expressed miRNAs in osteogenic (Figure S5A,B) and chondrogenic differentiation (Figure S5C,D). The results showed that target genes of upregulated miRNA in osteogenic differentiation are most enriched in pathways involved in neurotransmission, calcium, insulin, and AMPK signaling and in proteoglycans-related pathways, with one of the targets being CD44. The focal adhesion pathway (KEGG hsa04510) is enriched in targets of both upregulated and downregulated miRNAs in osteogenic differentiation. For chondrogenic differentiation, it is interesting to note the enrichment in $\mathrm{NF}-\mathrm{kB}$ and rheumatoid arthritis pathways for the targets of downregulated miRNA.

Table 3 reports the comparison of differentially expressed circRNA, which present binding sites for at least one of the differentially regulated miRNAs, with an exhaustive list for osteogenic differentiation. For chondrogenic differentiation, since we identified a plethora of possible interactions, only a selection 
of the circRNA-miRNA comparison is reported in Table 3, focusing on the circRNA derived from validated targets.

Table 3. Comparison between miRNA-binding sites of differentially expressed circRNA with the list of differentially expressed miRNAs in osteogenic differentiation. The pairs that presented an opposite direction of regulation are highlighted in bold.

\begin{tabular}{|c|c|c|c|c|}
\hline CircRNA ID & Best Transcript & $\begin{array}{l}\text { CircRNA Regulation in } \\
\text { OSTEO vs. CRL } \\
\text { Monolayer (Fold Change) }\end{array}$ & Binding Site For & $\begin{array}{l}\text { miRNA Regulation in } \\
\text { OSTEO vs. CRL } \\
\text { Monolayer (Fold change) }\end{array}$ \\
\hline hsa_circRNA_103249 & FBLN1 & Upregulated (2.28) & hsa-let-7i-5p & Downregulated (0.56) \\
\hline hsa_circRNA_405468 & $M T 2 A$ & Upregulated (2.00) & hsa-miR-450a-1-3p & Downregulated (0.62) \\
\hline hsa_circRNA_406308 & COL8A1 & Upregulated (2.04) & hsa-miR-548az-5p & Upregulated (1.86) \\
\hline hsa_circRNA_104864 & LPAR1 & Upregulated (1.68) & hsa-miR-7-5p & Upregulated (1.64) \\
\hline hsa_circRNA_057186 & AGPS & Upregulated (1.91) & hsa-miR-942-5p & Upregulated (1.59) \\
\hline hsa_circRNA_100835 & BSCL2 & Downregulated (0.49) & hsa-miR-199b-5p & Upregulated (2.65) \\
\hline CircRNA ID & Best Transcript & $\begin{array}{l}\text { CircRNA Regulation in } \\
\text { CHONDRO vs. CRL Pellet } \\
\text { (Fold Change) }\end{array}$ & Binding Site For & $\begin{array}{l}\text { miRNA Regulation in } \\
\text { CHONDRO vs. CRL Pellet } \\
\text { (Fold Change) }\end{array}$ \\
\hline hsa_circRNA_100833 & FADS2 & Upregulated (3.59) & $\begin{array}{c}\text { hsa-miR-665 } \\
\text { hsa-miR-495-3p }\end{array}$ & $\begin{array}{l}\text { Downregulated (0.37) } \\
\text { Downregulated }(0.54)\end{array}$ \\
\hline hsa_circRNA_100834 & FADS2 & Upregulated (2.29) & $\begin{array}{l}\text { hsa-miR-23b-5p } \\
\text { hsa-miR-299-3p }\end{array}$ & $\begin{array}{c}\text { Upregulated (4.13) } \\
\text { Downregulated (0.61) }\end{array}$ \\
\hline hsa_circRNA_035152 & FBN1 & Upregulated (1.92) & $\begin{array}{l}\text { hsa-miR-181a-5p } \\
\text { hsa-miR-181b-5p } \\
\text { hsa-miR-181d-5p }\end{array}$ & $\begin{array}{l}\text { Upregulated (3.89) } \\
\text { Upregulated (3.70) } \\
\text { Upregulated (1.82) }\end{array}$ \\
\hline hsa_circRNA_405335 & FBN1 & Upregulated (1.69) & $\begin{array}{l}\text { hsa-miR-181a-5p } \\
\text { hsa-miR-181b-5p } \\
\text { hsa-miR-181d-5p }\end{array}$ & $\begin{array}{l}\text { Upregulated (3.89) } \\
\text { Upregulated (3.70) } \\
\text { Upregulated (1.82) }\end{array}$ \\
\hline hsa_circRNA_100094 & HSPG2 & Upregulated (1.67) & hsa-miR-675-5p & Upregulated (24.65) \\
\hline hsa_circRNA_047037 & LDLRAD4 & Upregulated (2.01) & hsa-miR-2277-5p & Upregulated (1.52) \\
\hline hsa_circRNA_102854 & PDK1 & Upregulated (1.58) & $\begin{array}{l}\text { hsa-miR-30e-5p } \\
\text { hsa-miR-21-3p }\end{array}$ & $\begin{array}{l}\text { Upregulated (1.56) } \\
\text { Upregulated (2.29) }\end{array}$ \\
\hline hsa_circRNA_104119 & RUNX2 & Upregulated (1.52) & hsa-miR-7-5p & Upregulated (1.42) \\
\hline hsa_circRNA_104118 & $R U N X 2$ & Upregulated (1.66) & $\begin{array}{c}\text { hsa-miR-335-3p } \\
\text { hsa-miR-450a-2-3p }\end{array}$ & $\begin{array}{l}\text { Downregulated }(0.21) \\
\text { Downregulated }(0.60)\end{array}$ \\
\hline hsa_circRNA_073237 & VCAN & Upregulated (1.60) & hsa-miR-335-3p & Downregulated (0.21) \\
\hline hsa_circRNA_100582 & ZEB1 & Upregulated (1.58) & hsa-miR-148a-5p & Upregulated (2.57) \\
\hline hsa_circRNA_000782 & ZEB1 & Upregulated (1.59) & hsa-miR-148a-5p & Upregulated (2.57) \\
\hline hsa_circRNA_100511 & SMYD3 & Downregulated (0.65) & hsa-miR-181a-5p & Upregulated (3.89) \\
\hline hsa_circRNA_100512 & SMYD3 & Downregulated (0.61) & $\begin{array}{l}\text { hsa-miR-181a-5p } \\
\text { hsa-miR-181b-5p }\end{array}$ & $\begin{array}{l}\text { Upregulated (3.89) } \\
\text { Upregulated }(3.70)\end{array}$ \\
\hline hsa_circRNA_100509 & SMYD3 & Downregulated (0.64) & hsa-miR-671-5p & Upregulated (1.80) \\
\hline hsa_circRNA_102171 & SMURF2 & Downregulated (0.63) & hsa-let-7f-2-3p & Upregulated (1.72) \\
\hline
\end{tabular}

3.6. Differential Expression of Piwi-Interacting RNA in Early Osteo- and Chondrogenesis

RNA sequencing identified 8 upregulated and 46 downregulated piRNA in osteogenic differentiation vs. monolayer control, while 73 were upregulated and 58 downregulated in chondrogenic 
differentiation (Figure S6). Tables S7 and S8 show the full list of differentially expressed piRNA in osteogenic and in chondrogenic differentiation, respectively. The data are available in GEO series GSE135588 (https://www.ncbi.nlm.nih.gov/geo/query/acc.cgi?acc=GSE135588), subseries GSE135587 (https://www.ncbi.nlm.nih.gov/geo/query/acc.cgi?acc=GSE135587).

\subsection{Validation of miRNA and piRNA Expression}

The expression of different miRNA and piRNA has been analyzed by qPCR to validate their expression during osteo- or chondrogenesis. RNAseq analysis showed a downregulation of let-7i-5p expression during osteogenesis. A decrease during osteogenesis was also observed from qPCR analysis, which was consistent among donors as suggested by applying a ratio paired $t$-test, which resulted in a $p$-value $<0.01$. In addition, the overexpression of hsa-miR-5690 was confirmed in osteogenic differentiation (Figure 5), as no expression was detectable in day 7 control (monolayer) and with $\mathrm{Ct}$ values between 33 and 35 for osteogenic samples. Even though the same miRNA was upregulated in early chondrogenesis as from sequencing data, in this set of samples, the differential expression of hsa-miR-5690 was not confirmed, being mostly undetectable (data not shown). Moreover, in chondrogenic differentiation, the downregulation of hsa-miR-125b-5p and piR-hsa-23209 (DQ592931) and piR-hsa-2107 (DQ571813) was also observed by qPCR analysis, in comparison to the day 7 control (pellet; Figure 5).
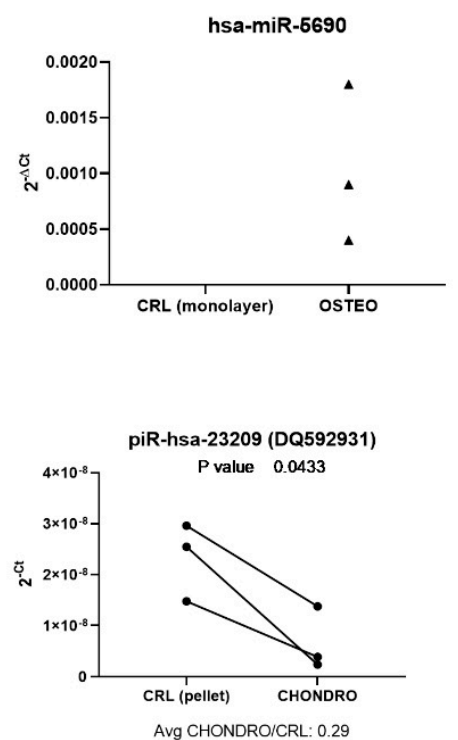
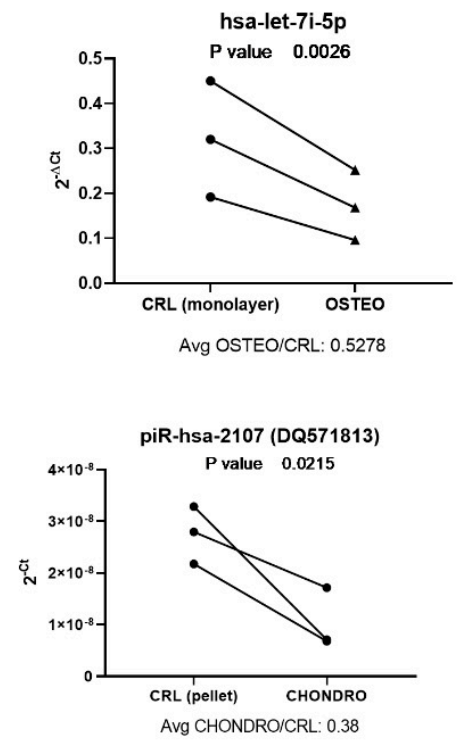

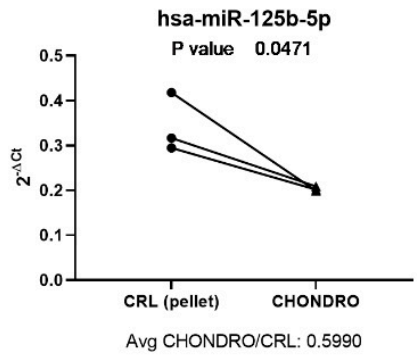

Avg CHONDRO/CRL: 0.5990

Figure 5. qPCR validation of miRNA and piRNA expression in early osteogenic or chondrogenic differentiation.

\section{Discussion}

In the present study, we have identified the differential expression of miRNA, piRNA, and circRNA in both osteogenic and chondrogenic differentiation of human MSCs. We have identified a set of differentially expressed circRNAs that, together with their parental gene, are implicated in a wide range of pathways important for cell fate determination, such as regulation of cyclic nucleotides for osteogenic differentiation, and collagen synthesis, FGF or TGF- $\beta$ signaling pathways in the commitment towards chondrogenic differentiation. While those pathways are known to regulate MSC differentiation, the involvement of circRNA has not been previously shown, and this opens the possibility to study how circRNA can act as regulators of signaling pathways and lineage commitment. In particular, the regulation of $B S C L 2$ in osteogenic differentiation is worth further investigation, as the circular and the total transcript showed opposite regulation. Moreover, its potential target hsa-miR-199b-5p was upregulated in the RNAseq analysis; this miRNA has been shown before to be upregulated during 
osteogenic differentiation and to target GSK-3 $\beta$, with a positive effect on $\beta$-catenin activation [48]. Another interesting target is represented by the LPAR1 gene, encoding for a lysophosphatidic acid receptor, whose absence has been previously shown to decrease bone mass [49]. Furthermore, the downregulation of circular FOXP1 in osteogenic differentiation (identified by RNAseq) is in accordance with a recent study that suggested a role for this circRNA in maintaining MSCs in a multipotent state [50].

The higher expression of COL1A1 and COL1A2 can potentially be explained with activation of pathways leading to endochondral differentiation, together with the observed upregulation of SPARC (which encodes for osteonectin, a bone extracellular matrix protein with affinity for collagen I and calcium). This is one of the well-known major limitations in chondrogenic pellet culture and controlling hypertrophy is one of the main challenges to tackle for cartilage tissue engineering [1]. Nevertheless, the expression of collagen type I is not limited to the hypertrophic cartilage, but it can also reflect its production in the superficial layers of the pellet. Moreover, we should keep in mind that a higher expression of the circular transcripts of COL1A1 and COL1A2 might regulate type I collagen fibril production. All the hypotheses are appealing but they should be tested with focused experiments and, after the initial identification of pathways, this will be one of the subjects for future research.

The expression of FKBP5, FADS2, ZEB1, and SMYD3 was evaluated in more detail. Indeed, they showed a similar regulation in osteogenic and in chondrogenic differentiation, and both differentiation protocols included dexamethasone, which was absent in the controls. The study of the expression of those genes included different steps. First, the differential expression of total FKBP5, FADS2, ZEB1, and SMYD3 was assessed by qPCR. Then, their levels were also measured in linear RNA-depleted samples. Moreover, after the validation of total and circular gene expression, we tested the hypothesis according to which dexamethasone may influence their regulation. To address this research question, we tested their expression in basal monolayer or pellet cultures, with or without treatment with dexamethasone or with the nonsteroidal selective glucocorticoid receptor agonist (+)-ZK216348, which retains transrepressional, but no significant transactivational, activity [51].

FKBP5 encodes for FK506 Binding Protein 5, an immunophilin that mediates the effects of immunosuppressant drugs [52]. Furthermore, it binds and inhibits the glucocorticoid receptor in a complex with heat shock proteins, regulating drug sensitivity [53,54], making it a likely candidate as target of dexamethasone in MSCs. The protein encoded by FADS2, $\Delta-6$ desaturase, is the rate-limiting enzyme for the synthesis of arachidonic acid from linoleic acid $[55,56]$. Only a few data have been published correlating glucocorticoids and FADS2 gene expression or protein activity; however, the effect of dexamethasone on FADS2 transcription may be tissue- and context-dependent, while it was suggested to have an inhibitory effect on enzyme activity [55,57-59]. ZEB1 is a transcriptional repressor: it inhibits IL2 gene expression [60] and it is reported as a central component in adipocytic differentiation [61] and for the repression of stemness-inhibiting miRNAs [62]. SMYD3 is a histone methyltransferase that activates the expression of oncogenes or cell-cycle associated genes, resulting in a proliferation of cancer cells [63].

Altogether, we demonstrate that total and circular FKBP5 are consistently upregulated in both osteogenic and chondrogenic differentiation and this effect is strongly associated with dexamethasone treatment, with likely involvement of the transactivation pathway.

The circular isoforms of ZEB1 were also upregulated in both differentiation lineages in the microarray donor cohort, with overall gene expression being significantly upregulated in early osteogenesis. For SMYD3, the decrease in the levels of the circular transcript did not reach statistical significance, although the trend towards a downregulation was consistent among donors. However, total SMYD3 was significantly less expressed in both osteo- and chondrogenic differentiation. The expression of ZEB1 and SMYD3 appeared to be at least partially controlled by dexamethasone. ZEB1 showed a trend towards a dexamethasone-dependent upregulation, which, however, reached statistical significance in pellet culture only. Similarly, SMYD3 was also downregulated by the glucocorticoid in 
monolayer culture. For these genes, the transactivation pathway is likely involved in their regulation, as (+)-ZK216348 did not show the same effect on gene expression levels.

On the contrary, FADS2 total expression was not confirmed, although a donor-specific response might be hypothesized, and its expression is influenced neither by dexamethasone or (+)-ZK216348. Circular forms of FADS2 RNA appear to be upregulated in the microarray donor cohort. Since $\Delta-6$ desaturase is involved in the production of eicosanoids, it is possible that this may be part of a mechanism of regulation of arachidonic acid and prostaglandin production. In this context, it should be mentioned that PGE2 has been shown to increase BMP-2 expression in human MSCs [64] and that high concentrations of arachidonic acid have also been associated with the inhibition of osteoblastogenesis and promotion of adipogenesis [65].

Regarding miRNAs, miR-5690 was the most upregulated miRNA on day 7 of osteogenic differentiation, and this was confirmed by qPCR analysis. Among the predicted targets of this miRNA, there are different components of Wnt signaling, such as WNT1, WNT3, and TCF7L1. miR-5690 also targets NOTCH3 and OSCAR, the latter encoding for an osteoclast-associated receptor which stimulates osteoclastogenesis. miR-5690 expression was previously shown in endothelial cells [66], but to our knowledge, it has never been associated with bone formation or cell differentiation. On the contrary, miR-125b-5p, which we showed to be downregulated in early chondrogenic differentiation, has been previously indicated to be associated with the attenuation of IL-1 $\beta$ target gene expression in osteoarthritic chondrocytes [67,68] and LPS-induced inflammation in ATDC5 cell line [69]. Moreover, it is downregulated by the activation of the NF-kB pathway [68] and targets SP7 (Osterix), an important transcription factor in osteogenic differentiation [70]. It is not completely known what the role of miR-125b-5p downregulation is in chondrogenic differentiation, although it may point to an involvement of the NF- $\mathrm{kB}$ pathway and hypertrophy.

Other papers have identified miRNAs associated with bone differentiation. For example, in the paper by Eguchi et al. [71], the authors identified some miRNAs that can play an important role during the osteogenesis of murine and human MSCs. In particular, the miR-30 family and miR-541 expression seem to regulate the expression of various genes crucial in cell differentiation. In our case, we found that different members of the miR-30 family could be potentially targeted by circRNAs, especially those who are downregulated in osteogenic differentiation. Also, circRNA in chondrogenic differentiation potentially targets this family. Moreover, RNAseq identified miR-30a-3p as upregulated in osteogenic differentiation. As for miR-541, the authors suggest an inhibitory function of this miRNA in osteogenesis as its antagomiR may increase osteopontin and ALP expression ultimately improving calcium deposition. However, miR-541 differential expression between osteogenic differentiation and the monolayer controls was not detected in our day 7 samples.

For the circRNA-miRNA comparison, the pairs with opposite direction (upregulated circRNA with downregulated miRNA and vice versa) are especially interesting as those circRNA could have a miRNA-sponging function. In osteogenic differentiation, FLBN1, MT2A, and BSCL2 represent three promising targets. In particular, both circular and total transcripts of $F B L N 1$ are overexpressed in osteogenic differentiation, and the let-7i-5p, a potential target of the circular transcript, is downregulated. In early chondrogenesis, an important role could be exerted by the circRNAs originated from SMYD3 gene. With dexamethasone controlling SMYD3 transcript formation at least in pellet culture, the overall transcript downregulation appears to be associated to a higher expression of miR-181a-5p, miR-181b-5p, and miR-671-5p (as identified from RNAseq). However, since SMYD3 protein has been associated to a specific transcriptional regulation of miRNA [72], whether this association is by a diminished miRNA sponging activity or not has yet to be demonstrated.

Finally, RNA sequencing identified several differentially regulated piRNAs. Even though piRNA are usually referred to as "guardians of the genome" for their role in protecting the germline from the activation of transposable elements, their regulation in somatic cells is becoming more evident in adult stem cells, cancer, and other diseases [7,11-14,16-18,73,74]. In this study, we have identified a total of 54 differentially expressed piRNA in osteogenic differentiation and 131 
in chondrogenic differentiation. In particular, the downregulation of two piRNA in chondrogenic differentiation was observed also by qPCR analysis: piR-hsa-23209 (DQ592931, previously reported in $[8,9,13,15]$ ) and piR-hsa-2107 (DQ571813, whose expression has been shown in $[8,75]$ ). After a search in piRNA dedicated databases such as piRBase (www.piRBase.org), piRNAdb (www.pirnadb.org), and piRNAQuest (http://bicresources.jcbose.ac.in/zhumur/pirnaquest/index.html), we found that DQ592931 overlaps with the region encoding for the Ro60-associated Y4 RNA on chromosome 6. DQ571813 shows alignment in nine different genomic regions on different chromosomes, where the piRNA may lie within intronic regions of the protein-coding VAC4 gene on chromosome 16 or associated with tRNA repeats (chromosomes 1-2-5-6-16-17). For both piRNAs, no potential target has been identified yet. Thus, functional studies will be needed to understand their role in differentiation and how to use them both as biomarkers or as functional targets for regenerative medicine strategies. Moreover, a limitation in the present piRNA validation analysis is represented by the lack of proper endogenous control for gene expression normalization. Although the RNA input was kept constant among all samples, we will need further confirmation of the results after the identification of a proper reference piRNA. Another limitation in the field of piRNA research is the lack of a standardized classification. The same piRNA could have different names based on the reference database. For example, the aliases for piRNA identified with the NCBI's accession number DQ571813 are hsa_piRNA_30146, hsa_piR_001312, piR-31925, or piR-hsa-2107. The same limitation is identified for circRNA: it can indeed be very difficult to compare different studies on circRNA since it is not always possible to link the circRNA named according to different databases. Overall, an effort in building a common nomenclature for piRNA and circRNA and increasing the functional annotations and identification of targets will be of great benefit, helping researchers in every field to discover new mechanisms of molecular regulation. An effort in this direction for circRNA is represented by Circbank [76], which suggests a novel naming system and collects functional annotations.

\section{Conclusions}

In conclusion, we have identified various non-coding RNAs that are differentially regulated in early osteogenic and chondrogenic differentiation. A set of 4 common genes that give rise to circRNA in both osteo- and chondrogenesis led to the identification of dexamethasone-dependent targets and more information on the relative amounts of circular transcript on total gene expression. This paves the way for further investigation to understand how dexamethasone controls the expression of those genes and what their function in MSC differentiation is. Overall, functional characterization and validation for the markers herein presented will be a necessary step towards understanding their role in mesenchymal stromal cell differentiation.

Supplementary Materials: The following are available online at http://www.mdpi.com/2073-4409/9/2/398/s1. Figure S1: Immunophenotype and differentiation potential of human bone marrow MSCs. Figure S2: Volcano plots were used for the visualization of differentially expressed circRNAs. Figure S3: Hierarchical clustering of differentially expressed miRNAs. Figure S4: Volcano plots were used for the visualization of differentially expressed miRNAs. Figure S5: KEGG pathway analysis for the target genes of differentially expressed miRNAs. Figure S6: Volcano plots were used for the visualization of differentially expressed piRNAs. Table S1: Summary of donor cohorts used for experiments. Table S2: List of assays used for qPCR validation of linear transcripts corresponding to differentially expressed circular RNAs. Table S3: Differentially expressed circRNA in osteogenic differentiation. Table S4: Full list of differentially expressed circRNA in chondrogenic differentiation. Table S5: Differentially expressed miRNA in osteogenic differentiation. Table S6: Differentially expressed miRNA in chondrogenic differentiation. Table S7: Differentially expressed piRNA in osteogenic differentiation. Table S8: Differentially expressed piRNA in chondrogenic differentiation.

Author Contributions: Conceptualization, M.A. and M.J.S. methodology, E.D.B., V.B., C.T. and U.M. data analysis and interpretation, E.D.B., V.B., C.T. and M.J.S. writing-original draft preparation, E.D.B. writing-review and editing, U.M., M.A., M.J.S. supervision, M.J.S. funding acquisition, M.J.S. All authors have read and agreed to the published version of the manuscript.

Funding: This Investigation was financially supported with the assistance of the AO Foundation via an AOTRAUMA Network grant.

Conflicts of Interest: The authors declare no conflict of interest. 


\section{References}

1. Armiento, A.R.; Alini, M.; Stoddart, M.J. Articular fibrocartilage-Why does hyaline cartilage fail to repair? Adv. Drug Deliv. Rev. 2018, 146, 289-305. [CrossRef] [PubMed]

2. Bara, J.J.; Richards, R.G.; Alini, M.; Stoddart, M.J. Concise review: Bone marrow-derived mesenchymal stem cells change phenotype following in vitro culture: Implications for basic research and the clinic. Stem Cells 2014, 32, 1713-1723. [CrossRef] [PubMed]

3. Clark, E.A.; Kalomoiris, S.; Nolta, J.A.; Fierro, F.A. Concise review: MicroRNA function in multipotent mesenchymal stromal cells. Stem Cells 2014, 32, 1074-1082. [CrossRef] [PubMed]

4. Huang, C.; Gou, S.; Wang, L.; Huang, K.; Liu, L.; Zhao, W.; Zheng, L.; Xiao, J. MicroRNAs and Peroxisome Proliferator-Activated Receptors Governing the Differentiation of Mesenchymal Stem Cells. Curr. Stem Cell Res. Ther. 2016, 11, 197-207. [CrossRef]

5. Li, N.; Long, B.; Han, W.; Yuan, S.; Wang, K. microRNAs: Important regulators of stem cells. Stem Cell. Res. Ther. 2017, 8, 110. [CrossRef]

6. Iwasaki, Y.W.; Siomi, M.C.; Siomi, H. PIWI-Interacting RNA: Its Biogenesis and Functions. Annu. Rev. Biochem. 2015, 84, 405-433. [CrossRef]

7. Han, Y.N.; Li, Y.; Xia, S.Q.; Zhang, Y.Y.; Zheng, J.H.; Li, W. PIWI Proteins and PIWI-Interacting RNA: Emerging Roles in Cancer. Cell. Physiol. Biochem. 2017, 44, 1-20. [CrossRef]

8. Girard, A.; Sachidanandam, R.; Hannon, G.J.; Carmell, M.A. A germline-specific class of small RNAs binds mammalian Piwi proteins. Nature 2006, 442, 199. [CrossRef]

9. Roovers, E.F.; Rosenkranz, D.; Mahdipour, M.; Han, C.-T.; He, N.; Chuva de Sousa Lopes, S.M.; van der Westerlaken, L.A.J.; Zischler, H.; Butter, F.; Roelen, B.A.J.; et al. Piwi Proteins and piRNAs in Mammalian Oocytes and Early Embryos. Cell Rep. 2015, 10, 2069-2082. [CrossRef]

10. Li, Y.; Wang, H.-Y.; Wan, F.-C.; Liu, F.-J.; Liu, J.; Zhang, N.; Jin, S.-H.; Li, J.-Y. Deep sequencing analysis of small non-coding RNAs reveals the diversity of microRNAs and piRNAs in the human epididymis. Gene 2012, 497, 330-335. [CrossRef]

11. Huang, G.; Hu, H.; Xue, X.; Shen, S.; Gao, E.; Guo, G.; Shen, X.; Zhang, X. Altered expression of piRNAs and their relation with clinicopathologic features of breast cancer. Clin. Transl. Oncol. 2013, 15, 563-568. [CrossRef]

12. Robine, N.; Lau, N.C.; Balla, S.; Jin, Z.; Okamura, K.; Kuramochi-Miyagawa, S.; Blower, M.D.; Lai, E.C. A broadly conserved pathway generates 3'UTR-directed primary piRNAs. Curr. Biol. 2009, 19, 2066-2076. [CrossRef] [PubMed]

13. Chu, H.; Hui, G.; Yuan, L.; Shi, D.; Wang, Y.; Du, M.; Zhong, D.; Ma, L.; Tong, N.; Qin, C.; et al. Identification of novel piRNAs in bladder cancer. Cancer Lett. 2015, 356, 561-567. [CrossRef] [PubMed]

14. van Wolfswinkel, J.C. Piwi and potency: PIWI proteins in animal stem cells and regeneration. Integr. Comp. Biol. 2014, 54, 700-713. [CrossRef] [PubMed]

15. Li, Y.; Wu, X.; Gao, H.; Jin, J.M.; Li, A.X.; Kim, Y.S.; Pal, S.K.; Nelson, R.A.; Lau, C.M.; Guo, C.; et al. Piwi-Interacting RNAs (piRNAs) Are Dysregulated in Renal Cell Carcinoma and Associated with Tumor Metastasis and Cancer-Specific Survival. Mol. Med. 2015, 21, 381-388. [CrossRef] [PubMed]

16. Busch, J.; Ralla, B.; Jung, M.; Wotschofsky, Z.; Trujillo-Arribas, E.; Schwabe, P.; Kilic, E.; Fendler, A.; Jung, K. Piwi-interacting RNAs as novel prognostic markers in clear cell renal cell carcinomas. J. Exp. Clin. Cancer Res. 2015, 34, 61. [CrossRef]

17. Juliano, C.; Wang, J.; Lin, H. Uniting germline and stem cells: the function of Piwi proteins and the piRNA pathway in diverse organisms. Annu. Rev. Genet. 2011, 45, 447-469. [CrossRef]

18. Hashim, A.; Rizzo, F.; Marchese, G.; Ravo, M.; Tarallo, R.; Nassa, G.; Giurato, G.; Santamaria, G.; Cordella, A.; Cantarella, C.; et al. RNA sequencing identifies specific PIWI-interacting small non-coding RNA expression patterns in breast cancer. Oncotarget 2014, 5, 9901-9910. [CrossRef]

19. Barrett, S.P.; Salzman, J. Circular RNAs: Analysis, expression and potential functions. Development 2016, 143, 1838-1847. [CrossRef]

20. Huang, S.; Yang, B.; Chen, B.J.; Bliim, N.; Ueberham, U.; Arendt, T.; Janitz, M. The emerging role of circular RNAs in transcriptome regulation. Genomics 2017, 109, 401-407. [CrossRef] 
21. Zheng, F.; Wang, M.; Li, Y.; Huang, C.; Tao, D.; Xie, F.; Zhang, H.; Sun, J.; Zhang, C.; Gu, C.; et al. CircNR3C1 inhibits proliferation of bladder cancer cells by sponging miR-27a-3p and downregulating cyclin D1 expression. Cancer Lett. 2019, 460, 139-151. [CrossRef] [PubMed]

22. Li, X.; Li, C.; Liu, Z.; Ni, W.; Yao, R.; Xu, Y.; Quan, R.; Zhang, M.; Li, H.; Liu, L.; et al. Circular RNA circ-FoxO3 Inhibits Myoblast Cells Differentiation. Cells 2019, 8, 616. [CrossRef] [PubMed]

23. Chi, Y.; Luo, Q.; Song, Y.; Yang, F.; Wang, Y.; Jin, M.; Zhang, D. Circular RNA circPIP5K1A promotes non-small cell lung cancer proliferation and metastasis through miR-600/HIF-1alpha regulation. J. Cell. Biochem. 2019, 120, 19019-19030. [CrossRef] [PubMed]

24. Yu, L.; Liu, Y. circRNA_0016624 could sponge miR-98 to regulate BMP2 expression in postmenopausal osteoporosis. Biochem. Biophys. Res. Commun. 2019, 516, 546-550. [CrossRef]

25. Chen, H.; Mao, M.; Jiang, J.; Zhu, D.; Li, P. Circular RNA CDR1as acts as a sponge of miR-135b-5p to suppress ovarian cancer progression. Onco Targets Ther. 2019, 12, 3869-3879. [CrossRef]

26. Lai, Z.; Yang, Y.; Wang, C.; Yang, W.; Yan, Y.; Wang, Z.; Xu, J.; Jiang, K. Circular RNA 0047905 acts as a sponge for microRNA4516 and microRNA1227-5p, initiating gastric cancer progression. Cell Cycle 2019, 18. [CrossRef]

27. Zhang, J.; Jiang, J.; Huang, R.; Wang, Y.; Nie, X.; Gui, R. Circular RNA expression profiles are significantly altered in mice bone marrow stromal cells after total body irradiation. Leuk. Res. 2018, 70, 67-73. [CrossRef]

28. Ren, W.; Yang, L.; Deng, T.; Wu, C.; Li, Y.; Wu, J.; Huang, Z.; Du, F.; Guo, L. Calcitonin gene-related peptide regulates FOSL2 expression and cell proliferation of BMSCs via mmu_circRNA_003795. Mol. Med. Report. 2019, 19, 3732-3742. [CrossRef]

29. Sun, B.; Shi, L.; Shi, Q.; Jiang, Y.; Su, Z.; Yang, X.; Zhang, Y. Circular RNAs are abundantly expressed and upregulated during repair of the damaged endometrium by Wharton's jelly-derived mesenchymal stem cells. Stem Cell. Res. Ther. 2018, 9, 314. [CrossRef]

30. Ruan, Z.-B.; Chen, G.-C.; Zhang, R.; Zhu, L. Circular RNA expression profiles during the differentiation of human umbilical cord-derived mesenchymal stem cells into cardiomyocyte-like cells. J. Cell. Physiol. 2019, 234, 16412-16423. [CrossRef]

31. Sun, X.; Jin, Y.; Liang, Q.; Tang, J.; Chen, J.; Yu, Q.; Li, F.; Li, Y.; Wu, J.; Wu, S. Altered expression of circular RNAs in human placental chorionic plate-derived mesenchymal stem cells pretreated with hypoxia. J. Clin. Lab. Anal. 2019, 33, e22825. [CrossRef]

32. Liu, R.; Chang, W.; Li, J.; Cheng, Y.; Dang, E.; Yang, X.; Wang, Q.; Wang, G.; Li, X.; Zhang, K. Mesenchymal stem cells in psoriatic lesions affect the skin microenvironment through circular RNA. Exp. Dermatol. 2019, 28, 292-299. [CrossRef]

33. Li, X.; Peng, B.; Zhu, X.; Wang, P.; Xiong, Y.; Liu, H.; Sun, K.; Wang, H.; Ou, L.; Wu, Z.; et al. Changes in related circular RNAs following ER $\beta$ knockdown and the relationship to rBMSC osteogenesis. Biochem. Biophys. Res. Commun. 2017, 493, 100-107. [CrossRef]

34. Zheng, Y.; Li, X.; Huang, Y.; Jia, L.; Li, W. The Circular RNA Landscape of Periodontal Ligament Stem Cells During Osteogenesis. J. Periodontol. 2017, 88, 906-914. [CrossRef]

35. Gu, X.; Li, M.; Jin, Y.; Liu, D.; Wei, F. Identification and integrated analysis of differentially expressed lncRNAs and circRNAs reveal the potential ceRNA networks during PDLSC osteogenic differentiation. BMC Genet. 2017, 18, 100. [CrossRef] [PubMed]

36. Li, X.; Zheng, Y.; Zheng, Y.; Huang, Y.; Zhang, Y.; Jia, L.; Li, W. Circular RNA CDR1as regulates osteoblastic differentiation of periodontal ligament stem cells via the miR-7/GDF5/SMAD and p38 MAPK signaling pathway. Stem Cell. Res. Ther. 2018, 9, 232. [CrossRef] [PubMed]

37. Peng, W.; Zhu, S.; Chen, J.; Wang, J.; Rong, Q.; Chen, S. Hsa_circRNA_33287 promotes the osteogenic differentiation of maxillary sinus membrane stem cells via miR-214-3p/Runx3. Biomed. Pharmacother. 2019, 109, 1709-1717. [CrossRef] [PubMed]

38. Zhang, M.; Jia, L.; Zheng, Y. circRNA Expression Profiles in Human Bone Marrow Stem Cells Undergoing Osteoblast Differentiation. Stem Cell Rev. 2019, 15, 126-138. [CrossRef] [PubMed]

39. Maass, P.G.; Glažar, P.; Memczak, S.; Dittmar, G.; Hollfinger, I.; Schreyer, L.; Sauer, A.V.; Toka, O.; Aiuti, A.; Luft, F.C.; et al. A map of human circular RNAs in clinically relevant tissues. J. Mol. Med. 2017, 95, 1179-1189. [CrossRef] [PubMed] 
40. Gardner, O.F.W.; Alini, M.; Stoddart, M.J. Mesenchymal Stem Cells Derived from Human Bone Marrow. In Cartilage Tissue Engineering: Methods and Protocols; Doran, P.M., Ed.; Springer: New York, NY, USA, 2015; pp. 41-52. [CrossRef]

41. Herrmann, M.; Hildebrand, M.; Menzel, U.; Fahy, N.; Alini, M.; Lang, S.; Benneker, L.; Verrier, S.; Stoddart, J.M.; Bara, J.J. Phenotypic Characterization of Bone Marrow Mononuclear Cells and Derived Stromal Cell Populations from Human Iliac Crest, Vertebral Body and Femoral Head. Int. J. Mol. Sci. 2019, 20, 3454. [CrossRef]

42. Della Bella, E.; Stoddart, M.J. Cell detachment rapidly induces changes in non-coding RNA expression in human mesenchymal stromal cells. Biotechniques. in press. [CrossRef]

43. Wang, J.; Zhang, P.; Chen, R.; He, S.; Li, Y.; Zheng, Y.; Lu, Y.; Kan, Y. piRBase: A comprehensive database of piRNA sequences. Nucleic Acids Res. 2018, 47, D175-D180. [CrossRef] [PubMed]

44. Zhang, P.; Si, X.; Skogerbø, G.; Wang, J.; Cui, D.; Li, Y.; Sun, X.; Liu, L.; Sun, B.; Chen, R.; et al. piRBase: A web resource assisting piRNA functional study. Database 2014, 2014. [CrossRef] [PubMed]

45. Ritchie, M.E.; Phipson, B.; Wu, D.; Hu, Y.; Law, C.W.; Shi, W.; Smyth, G.K. limma powers differential expression analyses for RNA-sequencing and microarray studies. Nucleic Acids Res. 2015, 43, e47. [CrossRef] [PubMed]

46. Loebel, C.; Czekanska, E.M.; Bruderer, M.; Salzmann, G.; Alini, M.; Stoddart, M.J. In vitro osteogenic potential of human mesenchymal stem cells is predicted by Runx2/Sox9 ratio. Tissue Eng. Part A 2015, 21, 115-123. [CrossRef] [PubMed]

47. Edgar, R.; Domrachev, M.; Lash, A.E. Gene Expression Omnibus: NCBI gene expression and hybridization array data repository. Nucleic Acids Res. 2002, 30, 207-210. [CrossRef]

48. Zhao, R.; Li, Y.; Lin, Z.; Wan, J.; Xu, C.; Zeng, Y.; Zhu, Y. miR-199b-5p modulates BMSC osteogenesis via suppressing GSK-3beta/beta-catenin signaling pathway. Biochem. Biophys. Res. Commun. 2016, 477, 749-754. [CrossRef]

49. Gennero, I.; Laurencin-Dalicieux, S.; Conte-Auriol, F.; Briand-Mesange, F.; Laurencin, D.; Rue, J.; Beton, N.; Malet, N.; Mus, M.; Tokumura, A.; et al. Absence of the lysophosphatidic acid receptor LPA1 results in abnormal bone development and decreased bone mass. Bone 2011, 49, 395-403. [CrossRef]

50. Cherubini, A.; Barilani, M.; Rossi, R.L.; Jalal, M.M.K.; Rusconi, F.; Buono, G.; Ragni, E.; Cantarella, G.; Simpson, H.; Peault, B.; et al. FOXP1 circular RNA sustains mesenchymal stem cell identity via microRNA inhibition. Nucleic Acids Res. 2019, 47, 5325-5340. [CrossRef]

51. Schäcke, H.; Schottelius, A.; Döcke, W.-D.; Strehlke, P.; Jaroch, S.; Schmees, N.; Rehwinkel, H.; Hennekes, H.; Asadullah, K. Dissociation of transactivation from transrepression by a selective glucocorticoid receptor agonist leads to separation of therapeutic effects from side effects. Proc. Natl. Acad. Sci. USA 2004, 101, 227-232. [CrossRef]

52. Jiang, W.; Cazacu, S.; Xiang, C.; Zenklusen, J.C.; Fine, H.A.; Berens, M.; Armstrong, B.; Brodie, C.; Mikkelsen, T. FK506 binding protein mediates glioma cell growth and sensitivity to rapamycin treatment by regulating NF-kappaB signaling pathway. Neoplasia 2008, 10, 235-243. [CrossRef] [PubMed]

53. Egeland, M.; Zunszain, P.A.; Pariante, C.M. Molecular mechanisms in the regulation of adult neurogenesis during stress. Nat. Rev. Neurosci. 2015, 16, 189-200. [CrossRef] [PubMed]

54. Binder, E.B. The role of FKBP5, a co-chaperone of the glucocorticoid receptor in the pathogenesis and therapy of affective and anxiety disorders. Psychoneuroendocrinology 2009, 34, S186-S195. [CrossRef] [PubMed]

55. Stojadinovic, O.; Lee, B.; Vouthounis, C.; Vukelic, S.; Pastar, I.; Blumenberg, M.; Brem, H.; Tomic-Canic, M. Novel genomic effects of glucocorticoids in epidermal keratinocytes: inhibition of apoptosis, interferon-gamma pathway, and wound healing along with promotion of terminal differentiation. J. Biol. Chem. 2007, 282, 4021-4034. [CrossRef]

56. He, C.; Qu, X.; Wan, J.; Rong, R.; Huang, L.; Cai, C.; Zhou, K.; Gu, Y.; Qian, S.Y.; Kang, J.X. Inhibiting Delta-6 Desaturase Activity Suppresses Tumor Growth in Mice. PLoS ONE 2012, 7, e47567. [CrossRef]

57. Pickering, R.T.; Lee, M.-J.; Karastergiou, K.; Gower, A.; Fried, S.K. Depot Dependent Effects of Dexamethasone on Gene Expression in Human Omental and Abdominal Subcutaneous Adipose Tissues from Obese Women. PLoS ONE 2016, 11, e0167337. [CrossRef]

58. Saether, T.; Tran, T.N.; Rootwelt, H.; Christophersen, B.O.; Haugen, T.B. Expression and regulation of delta5-desaturase, delta6-desaturase, stearoyl-coenzyme A (CoA) desaturase 1, and stearoyl-CoA desaturase 2 in rat testis. Biol. Reprod. 2003, 69, 117-124. [CrossRef] 
59. Marra, C.A.; de Alaniz, M.J.; Brenner, R.R. Modulation of delta 6 and delta 5 rat liver microsomal desaturase activities by dexamethasone-induced factor. Biochim. Biophys. Acta 1986, 879, 388-393. [CrossRef]

60. Williams, T.M.; Moolten, D.; Burlein, J.; Romano, J.; Bhaerman, R.; Godillot, A.; Mellon, M.; Rauscher, F.J., 3rd; Kant, J.A. Identification of a zinc finger protein that inhibits IL-2 gene expression. Science 1991, 254, 1791-1794. [CrossRef]

61. Gubelmann, C.; Schwalie, P.C.; Raghav, S.K.; Röder, E.; Delessa, T.; Kiehlmann, E.; Waszak, S.M.; Corsinotti, A.; Udin, G.; Holcombe, W.; et al. Identification of the transcription factor ZEB1 as a central component of the adipogenic gene regulatory network. eLife 2014, 3, e03346. [CrossRef]

62. Wellner, U.; Schubert, J.; Burk, U.C.; Schmalhofer, O.; Zhu, F.; Sonntag, A.; Waldvogel, B.; Vannier, C.; Darling, D.; zur Hausen, A.; et al. The EMT-activator ZEB1 promotes tumorigenicity by repressing stemness-inhibiting microRNAs. Nat. Cell Biol. 2009, 11, 1487-1495. [CrossRef] [PubMed]

63. Hamamoto, R.; Furukawa, Y.; Morita, M.; Iimura, Y.; Silva, F.P.; Li, M.; Yagyu, R.; Nakamura, Y. SMYD3 encodes a histone methyltransferase involved in the proliferation of cancer cells. Nat. Cell Biol. 2004, 6, 731-740. [CrossRef] [PubMed]

64. Arikawa, T.; Omura, K.; Morita, I. Regulation of bone morphogenetic protein-2 expression by endogenous prostaglandin E2 in human mesenchymal stem cells. J. Cell. Physiol. 2004, 200, 400-406. [CrossRef]

65. Casado-Diaz, A.; Santiago-Mora, R.; Dorado, G.; Quesada-Gomez, J.M. The omega-6 arachidonic fatty acid, but not the omega-3 fatty acids, inhibits osteoblastogenesis and induces adipogenesis of human mesenchymal stem cells: potential implication in osteoporosis. Osteoporos. Int. 2013, 24, 1647-1661. [CrossRef] [PubMed]

66. Van Balkom, B.W.; Eisele, A.S.; Pegtel, D.M.; Bervoets, S.; Verhaar, M.C. Quantitative and qualitative analysis of small RNAs in human endothelial cells and exosomes provides insights into localized RNA processing, degradation and sorting. J. Extr. Vesicles 2015, 4, 26760. [CrossRef] [PubMed]

67. Matsukawa, T.; Sakai, T.; Yonezawa, T.; Hiraiwa, H.; Hamada, T.; Nakashima, M.; Ono, Y.; Ishizuka, S.; Nakahara, H.; Lotz, M.K.; et al. MicroRNA-125b regulates the expression of aggrecanase-1 (ADAMTS-4) in human osteoarthritic chondrocytes. Arthritis Res. Ther. 2013, 15, R28. [CrossRef]

68. Rasheed, Z.; Rasheed, N.; Abdulmonem, W.A.; Khan, M.I. MicroRNA-125b-5p regulates IL-1 $\beta$ induced inflammatory genes via targeting TRAF6-mediated MAPKs and NF- $\kappa$ B signaling in human osteoarthritic chondrocytes. Sci. Rep. 2019, 9, 6882. [CrossRef]

69. Jia, J.; Wang, J.; Zhang, J.; Cui, M.; Sun, X.; Li, Q.; Zhao, B. MiR-125b Inhibits LPS-Induced Inflammatory Injury via Targeting MIP-1alpha in Chondrogenic Cell ATDC5. Cell. Physiol. Biochem. 2018, 45, 2305-2316. [CrossRef]

70. Goettsch, C.; Rauner, M.; Pacyna, N.; Hempel, U.; Bornstein, S.R.; Hofbauer, L.C. miR-125b regulates calcification of vascular smooth muscle cells. Am. J. Pathol. 2011, 179, 1594-1600. [CrossRef]

71. Eguchi, T.; Watanabe, K.; Hara, E.S.; Ono, M.; Kuboki, T.; Calderwood, S.K. OstemiR: a novel panel of microRNA biomarkers in osteoblastic and osteocytic differentiation from mesencymal stem cells. PLoS ONE 2013, 8, e58796. [CrossRef]

72. Chen, D.; Liu, L.; Luo, X.; Mu, A.; Yan, L.; Chen, X.; Wang, L.; Wang, N.; He, H.; Zhou, H.; et al. Effect of SMYD3 on the microRNA expression profile of MCF-7 breast cancer cells. Oncol. Lett. 2017, 14, 1831-1840. [CrossRef] [PubMed]

73. Torres, A.G.; Reina, O.; Stephan-Otto Attolini, C.; Ribas de Pouplana, L. Differential expression of human tRNA genes drives the abundance of tRNA-derived fragments. Proc. Natl. Acad. Sci. USA 2019, 116, 8451-8456. [CrossRef] [PubMed]

74. Roy, J.; Sarkar, A.; Parida, S.; Ghosh, Z.; Mallick, B. Small RNA sequencing revealed dysregulated piRNAs in Alzheimer's disease and their probable role in pathogenesis. Mol. Biosyst. 2017, 13, 565-576. [CrossRef] [PubMed]

75. Krawetz, S.A.; Kruger, A.; Lalancette, C.; Tagett, R.; Anton, E.; Draghici, S.; Diamond, M.P. A survey of small RNAs in human sperm. Hum. Reprod. 2011, 26, 3401-3412. [CrossRef] [PubMed]

76. Liu, M.; Wang, Q.; Shen, J.; Yang, B.B.; Ding, X. Circbank: A comprehensive database for circRNA with standard nomenclature. RNA Biol. 2019, 16, 899-905. [CrossRef] 